\section{Check for updates}

Cite this: Nanoscale Adv., 2019, 1, 1276

\title{
Will organic-inorganic hybrid halide lead perovskites be eliminated from optoelectronic applications?
}

\author{
Zijun Yi, ${ }^{\text {ab }}$ Najib Haji Ladi, ${ }^{\text {b }}$ Xuxia Shai, ${ }^{a}$ Hao Li, ${ }^{a}$ Yan Shen (D) a and Mingkui Wang (D) *a
}

In the development of perovskite solar cells, a new version of Don Quixote is needed if scientists are to keep on seeking the most celebrated works of literature, according to the evaluation criterion of 'THE FIRST' and 'THE BEST'. Perovskite solar cells have developed rapidly in recent years due to several factors, including their high light absorption capability, long carrier lifetime, high defect tolerance, and adjustable band gap. Since they were first reported in 2009, solar cells based on organic-inorganic hybrid halide lead perovskites have achieved a power conversion efficiency of over $23 \%$. However, although there are broad development prospects for perovskite solar cells, their lead toxicity and instability resulting from the use of organic-inorganic hybrid halide lead perovskites such as $\mathrm{CH}_{3} \mathrm{NH}_{3} \mathrm{Pbl}_{3}$ limit their application, which is further deteriorating progressively. Therefore, the development of environmentally friendly, stable and efficient perovskite materials for future optoelectronic applications has long-term practical significance, which can eventually be commercialized. In this case, the discovery and development of inorganic lead-free perovskite light absorbing materials have become an active research topic in the field of photovoltaics. In this review, we discuss the application of organic-inorganic hybrid halide lead perovskites. This application is further analyzed and summarized using the research progress on inorganic lead-free perovskite solar cells by restoring some relevant prospects for the development of inorganic lead-free perovskite solar cells.

Received 25th December 2018

Accepted 16th January 2019

DOI: $10.1039 / c 8 n a 00416 a$

rsc.li/nanoscale-advances

\section{Introduction}

The imminent energy crisis and climate change associated with the use of traditional fossil fuels require the development of renewable energy technologies. Among them, photovoltaics (PV) (converting sunlight to electricity) represents one of the most promising approaches. Currently, silicon-based PVs have thoroughly dominated the market. ${ }^{1}$ However, new technologies are always welcome in the field of solar cells considering a reduction in fabrication cost, including high-temperature processing for silicon cells. One such alternative method involves replacing the crystalline silicon active layers with socalled organic semiconductors. ${ }^{2}$ The key advantage of this approach is the possibility of using solution processing technology to manufacture solar modules, which greatly reduces the cost and energy investment payback time simultaneously.

The manufacturing cost of mainstream silicon solar cell technology has declined sharply to ensure the large-scale use of $\mathrm{PV}$ technology in the future, and the latest investigations with

${ }^{a}$ Wuhan National Laboratory for Optoelectronics, Huazhong University of Science and Technology, Luoyu Road 1037, Wuhan 430074, P. R. China. E-mail: mingkui.wang@ mail.hust.edu.cn

${ }^{b}$ China-EU Institute for Clean and Renewable Energy, Huazhong University of Science and Technology, Luoyu Road 1037, Wuhan 430074, P. R. China extended data have predicted that PV technology can contribute nearly one-third of the new power generation globally between now and 2030. ${ }^{3}$ Undoubtedly, several factors such as cost and manufacturing difficulties have stimulated new photovoltaic technologies. ${ }^{4}$ Emerging technologies including organic-inorganic halide perovskites-based solar cells can significantly improve the energy conversion efficiency and considerably reduce processing costs. These type of solar cells can be often prepared via solution-based methods, which have low equipment requirements and simple preparation processed, which makes it suitable for large-scale commercial production.

In recent years, the use of PV containing organic-inorganic halide lead perovskite compounds has expanded rapidly. ${ }^{5}$ The most studied perovskite solar cells (PSCs) are organic-inorganic halide perovskites based on the $\mathrm{ABX}_{3}$ formula, in which $\mathrm{A}$ is a monovalent organic cation $\left(\mathrm{CH}_{3} \mathrm{NH}_{3}{ }^{+}=\mathrm{MA}^{+}, \mathrm{CH}\left(\mathrm{NH}_{2}\right)_{2}{ }^{+}=\right.$ $\mathrm{FA}^{+}$) or an inorganic metal cation $\left(\mathrm{Cs}^{+}\right.$and $\left.\mathrm{Rb}^{+}\right), \mathrm{B}$ is a divalent metal cation $\left(\mathrm{Pb}^{2+}, \mathrm{Sn}^{2+}, \mathrm{Ge}^{2+}, \mathrm{Mg}^{2+}\right.$, and $\left.\mathrm{Ca}^{2+}\right)$ and $\mathrm{X}$ is a halide ion $\left(\mathrm{Cl}^{-}, \mathrm{Br}^{-}\right.$and $\left.\mathrm{I}^{-}\right) .{ }^{6}$ The power conversion efficiency (PCE) of small-sized PSCs jumped from $3.8 \%$ to $23.3 \%$, which is close to their commercial competitors such as polysilicon, cadmium telluride (CdTe) and copper indium gallium selenide (CIGS) solar cells. ${ }^{7}$ This outstanding performance can be attributed to the characteristics of halide perovskites with a high bipolar charge carrier mobility (around $0.6 \mathrm{~cm}^{2} \mathrm{~V}^{-1} \mathrm{~s}^{-1}$ ), ${ }^{8}$ balanced 
electron and hole transport, long carrier diffusion length, high absorption coefficient and direct and adjustable band gap. ${ }^{9}$

Although the PCE of organic-inorganic hybrid PSCs has already met one of the prerequisites for commercialization (PCE $>15 \%$ ), their device stability and $\mathrm{Pb}$ toxicity are still two major challenges. ${ }^{10}$ Although several important works have claimed that PSC systems (unit cell and module) using inorganicorganic hybrid perovskite compounds or their counterparts and all inorganic compounds in combination with inorganic/ organic charge carriers are stable under thermal or light stress with or without tracing a maximum power point during the accelerated aging testing, most of the results are unable to be reproduced in the field. This is quite a realistic point to be considered. Consequently, effective strategies must be proposed to overcome the toxicity of lead and environmental hazards of lead-containing products, as well as chemical instability under ambient conditions (especially in the presence of air, humidity, and light) (Fig. 1).

Currently, PV devices are mainly installed outdoors, which means solar cells must be able to operate in real conditions. This requires no degradation when the devices are exposed to environmental conditions such as oxygen and moisture. To date, the $\mathrm{MAPbI}_{3}$ perovskite has been the most widely investigated due to its good film formation and optoelectronic properties. However, there are at least four key factors that can lead to the degradation of $\mathrm{MAPbI}_{3}$ perovskite films: oxygen, moisture, UV exposure, and temperature. ${ }^{1}$ For example, when exposed to water, due to the hygroscopic nature of their organic components, these materials are spontaneously affected by moisture ingress and subsequently degradation. ${ }^{\mathbf{1 1}} \mathrm{A}$ series of reactions can take place during the degradation of $\mathrm{MAPbI}_{3}{ }^{\mathbf{1 , 8 , 1 1 , 1 2}}$ which can be expressed as follows

$$
\begin{gathered}
\mathrm{CH}_{3} \mathrm{NH}_{3} \mathrm{PbI}_{3} \stackrel{\mathrm{H}_{2} \mathrm{O}}{\longrightarrow} \mathrm{CH}_{3} \mathrm{NH}_{3} \mathrm{I}(\mathrm{aq})+\mathrm{PbI}_{2}(\mathrm{~s}) \\
\mathrm{CH}_{3} \mathrm{NH}_{3} \mathrm{I}(\mathrm{aq}) \rightarrow \mathrm{CH}_{3} \mathrm{NH}_{2}(\mathrm{aq})+\mathrm{HI}(\mathrm{aq}) \\
4 \mathrm{HI}(\mathrm{aq})+\mathrm{O}_{2} \rightarrow 2 \mathrm{I}_{2}(\mathrm{~s})+2 \mathrm{H}_{2} \mathrm{O} \\
2 \mathrm{HI}(\mathrm{aq}) \stackrel{h v}{\rightarrow} \mathrm{H}_{2} \uparrow+2 \mathrm{I}_{2}(\mathrm{~s})
\end{gathered}
$$

Ultraviolet light can also cause the degradation of $\mathrm{MAPbI}_{3}$ perovskite. For example, the commonly used $\mathrm{TiO}_{2}$ electron

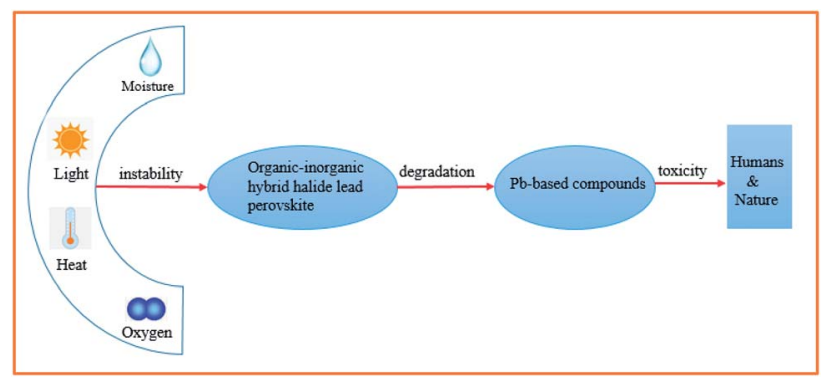

Fig. 1 Schematic of the instability and toxicity of organic-inorganic hybrid halide lead perovskite compounds. transport layer for these PSCs is susceptible to UV-induced degradation. According to the international standards for climate chamber tests (IEC 61646), solar cells need to maintain long-term stability at $85{ }^{\circ} \mathrm{C}(=358.15 \mathrm{~K}) .{ }^{13}$ The thermal energy at $85{ }^{\circ} \mathrm{C}$ corresponds to $0.093 \mathrm{eV}$, which is very close to the absolute value of formation energy of $\mathrm{MAPbI}_{3}(0.11-0.14 \mathrm{eV})$ obtained from density functional theory (DFT). This indicates that $\mathrm{MAPbI}_{3}$ is intrinsically unstable when continuously exposed to high temperature, which can cause thermal stress. ${ }^{14-23}$ Its temperature-induced decomposition can take place as follows

$$
\mathrm{CH}_{3} \mathrm{NH}_{3} \mathrm{PbI}_{3} \rightarrow \mathrm{CH}_{3} \mathrm{NH}_{2} \uparrow+\mathrm{HI} \uparrow+\mathrm{PbI}_{2} \text { (s) exceeding } 100{ }^{\circ} \mathrm{C}
$$

In order to improve the chemical stability of $\mathrm{MAPbI}_{3}$-based PSCs against moisture and temperature, researchers have proposed exchanging the $\mathrm{MA}^{+}$organic cation with another component at the A position. For example, $\mathrm{FAPbI}_{3}$ has been shown to be more thermally stable than $\mathrm{MAPbI}_{3}$ due to its larger tolerance factor. However, $\mathrm{FAPbI}_{3}$ undergoes a phase transition from the black triangle perovskite $\alpha-\mathrm{FAPbI}_{3}$ phase to the yellow hexagonal $\delta$ - $\mathrm{FAPbI}_{3}$ phase in the presence of moisture. ${ }^{\mathbf{1 8 , 2 4}}$ Considering the instability of organic cations $\left(\mathrm{MA}^{+}\right.$and $\left.\mathrm{FA}^{+}\right)$, researchers believe that the utilization of inorganic cations $\left(\mathrm{Cs}^{+}\right)$ instead of organic cations can improve the stability of perovskite materials. It should be noted that the trend on the claimed stability of PSCs by changing $\mathrm{MA}^{+}$to $\mathrm{FA}^{+}$and then $\mathrm{Cs}^{+}$has actually shown that, unfortunately, this is not a final solution for the above-mentioned challenges.

Nevertheless, due to their lack of structural stability over thousands of hours, these devices are unappealing for commercial applications, regardless of the developments in device performance. Furthermore, there is currently an intense debate on the use of lead in PSCs, which is believed to be the key component for most perovskites for effective PV. ${ }^{25-27}$ Though it is for sure that the lead causes toxic problems during device manufacture, deployment, and disposal. In contrast to lead acid batteries, which are composed of $\left(\mathrm{PbSO}_{4}\right.$ and $\left.\mathrm{PbO}\right)$ highly waterinsoluble compounds, $\mathrm{MAPbI}_{3}$ perovskite is easily decomposed into $\mathrm{PbI}_{2}$ with a solubility of $4.4 \times 10^{-9}$ in $\mathrm{H}_{2} \mathrm{O}$ at room temperature. ${ }^{28}$ For typical $\mathrm{MAPbI}_{3}$ perovskite solar cells, $\mathrm{PbI}_{2}$, hydroiodic acid (HI) and methylamine produced by the decomposition of perovskite may have adverse effects on the environment. ${ }^{29}$ According to the World Health Organization (WHO), the $50 \%$ lethal dose of lead $\left[\mathrm{LD}_{50}(\mathrm{~Pb})\right]$ is less than $5 \mathrm{mg}$ $\mathrm{kg}^{-1}$ of body weight. Since the WHO has stipulated that the highest blood lead level is $5 \mathrm{mg} \mathrm{L}^{-1}$ in children, it is difficult for $\mathrm{Pb}$-based perovskites to pass environmental standards for PV systems. ${ }^{28-31}$ Hence, the toxicity of lead-based perovskites has become another obvious problem due to the possibility of lead leaching into the environment.

Thus, the key issues of poor device stability associated with intrinsic material instability and toxicity due to water-soluble $\mathrm{Pb}^{2+}$ need to be addressed before large-scale commercialization of perovskite. ${ }^{26,32-34}$ Herein, two approaches may be effective to address the above-mentioned challenges in the future: suitable encapsulation and new inorganic lead-free perovskite 

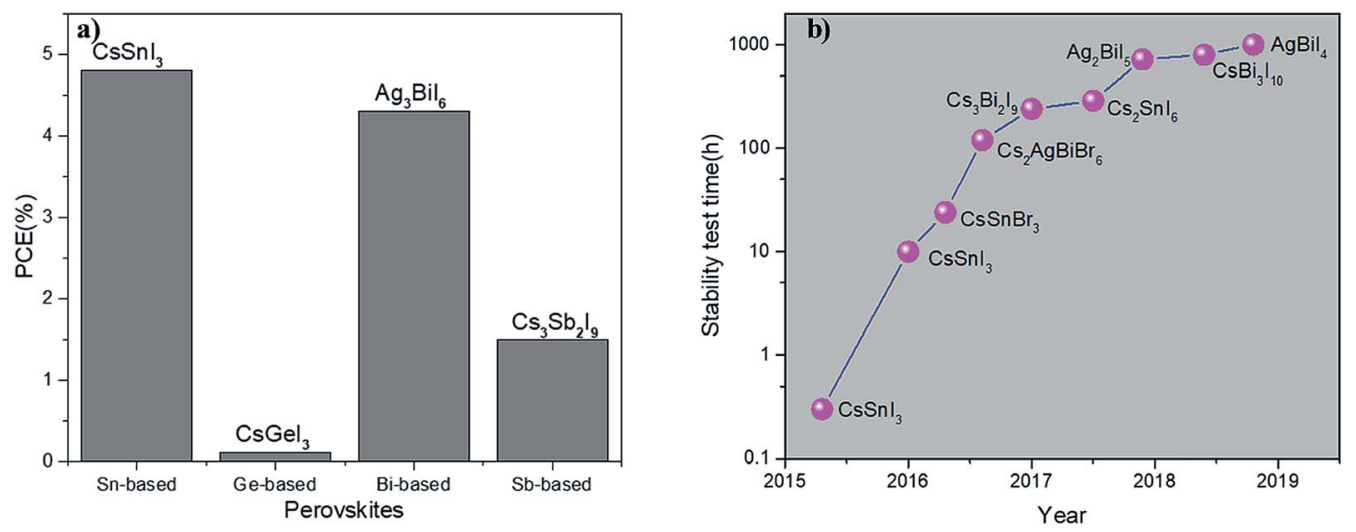

Fig. 2 (a) Highest PCE of devices based on different inorganic lead-free perovskite materials reported to date (classified by element). (b) Stability test time evolution of inorganic lead-free perovskites.

materials. We believe the latter can be an effective strategy from a scientific point of view after evaluating the strategy from the First Solar CdS cells. Therefore, after about ten years of thorough investigation into this type of material, it is essential for scientists to question whether the elimination of organicinorganic hybrid halide lead perovskites (especially $\mathrm{MAPbI}_{3}$ ) from PV application is necessary or not. To date, several groups in this research community have vaguely proven their solution to this problem without any official statement. Thus, it is crucial to test alternatives to achieve similar optical and photovoltaic performances for the commercialization of PSCs. Several research groups have begun to replace lead with other elements and replace organic cations with inorganic cations to form suitable new non-toxic and stable perovskite materials (Fig. 2), which may be a long journey before the final commercialization of PSCs. ${ }^{7,35-39}$ Therefore, this review focuses on the research progress on inorganic lead-free perovskites and their application in photovoltaics in recent years, with the aim to clarify the development of the existing problems.

\section{Perovskite formation and structural consideration}

Perovskite compounds are classified into inorganic oxide perovskites, alkali metal halide perovskites, and organic metal halide perovskites. They are represented by the structural formula $\mathrm{ABX}_{3}$, where $\mathrm{B}$ is a metal cation and $\mathrm{X}$ is an anion composed of oxides or halides. The $\mathrm{B}$ and $\mathrm{X}$ ions form the $\mathrm{BX}_{6}$ octahedra with $\mathrm{B}$ in the center and $\mathrm{X}$ in the corner. By connecting the corners, the $\mathrm{BX}_{6}$ octahedra extend to form a threedimensional structure (Fig. 3). ${ }^{18}$

The formation of metal halide perovskite depends on three factors: (1) the charge neutrality between the anions and cations, (2) the stability of the $\mathrm{BX}_{6}$ octahedron predicted by the octahedral factor $\mu$, and (3) the ionic radii of A, B and X are in accordance with the requirements of the Goldschmidt tolerance factor $\mathrm{t}^{9}{ }^{9}$ The octahedral factor $\mu$, which is the ratio of the radius of the B-site cation $\left(r_{\mathrm{B}}\right)$ and the halide counter ion $\left(r_{\mathrm{X}}\right)$, can be used to estimate the thermal stability of the $\mathrm{BX}_{6}$ octahedra (eqn
(6)). The binding of the B-site cation is determined by the ion size limitations defined by the $\mathrm{X}_{6}$ octahedra. For a value of $\mu$ between 0.442 and 0.895 , the metal halide perovskite has been found to be stable.

$$
\mu=\frac{r_{\mathrm{B}}}{r_{\mathrm{X}}}
$$

The Goldschmidt tolerance factor $t$ is calculated to apply the ionic radii of the involved $\mathrm{A}, \mathrm{B}$ and $\mathrm{X}$ ions $\left(r_{\mathrm{A}}, r_{\mathrm{B}}\right.$ and $\left.r_{\mathrm{X}}\right)$ according to eqn (7)..$^{13}$ It can be used to evaluate whether different types of $\mathrm{A}, \mathrm{B}$ and $\mathrm{X}$ ions can form the perovskite structure.

$$
t=\frac{\left(r_{\mathrm{A}}+r_{\mathrm{X}}\right)}{\sqrt{2}\left(r_{\mathrm{B}}+r_{\mathrm{X}}\right)}
$$

Based on the limitation of ion sizes for the cations and anions involved, the stability and formability of the $\mathrm{ABX}_{3}$ perovskite structure can be determined. ${ }^{40}$ The tolerance coefficient is empirically found to be $0.8 \leq t \leq 1.0$. For example, a tolerance coefficient of 1.0 indicates the formation of an ideal $\mathrm{ABX}_{3}$-type perovskite having a cubic crystal structure. If the tolerance coefficient is between 0.9 and 1.0, the perovskite will form a cubic crystal structure. In the case of a $t$ between 0.80 and 0.89 , a distorted perovskite structure with an orthorhombic, tetragonal, or rhombohedral crystal structure is most likely to be formed (Fig. 4). Whereas, if the value of $t$ is less than 0.8 , then the A cation is too small to form a perovskite structure, and will form an alternative structure such as ilmenite-type $\mathrm{FeTiO}_{3}$. Also for a $t$ greater than 1 , the A cation is too large to form a perovskite structure, where a hexagonal structure will be formed instead of layers that, which includes face-sharing octahedra. ${ }^{941-45}$

The concept of the Goldschmidt tolerance factor works reasonably with the organic-inorganic metal halide perovskite materials. Furthermore, many researchers have used this parameter to determine whether a combination of several ions can form a stable perovskite structure. In addition, this is also the basis for assessing the feasibility of homovalent or 

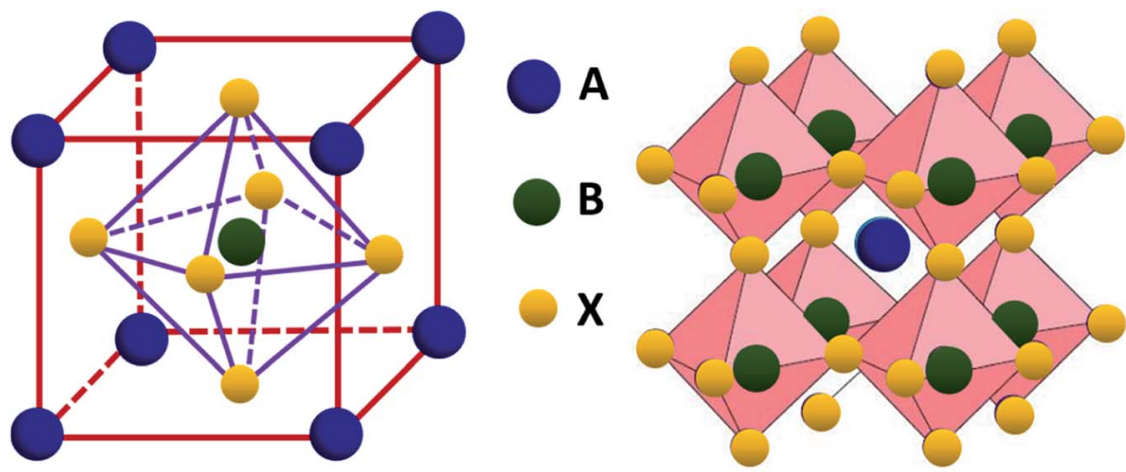

Fig. 3 Structure of perovskites with $\mathrm{ABX}_{3}$ formula.

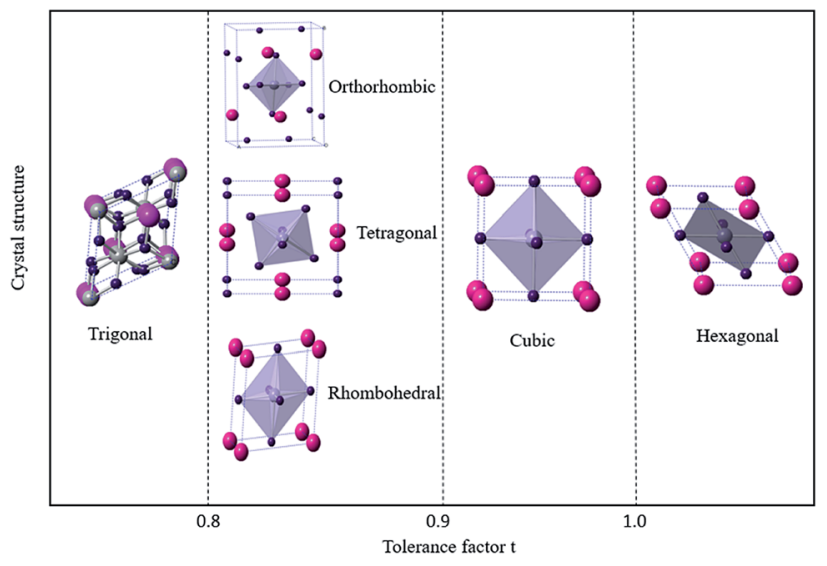

Fig. 4 Correlation between the crystal structure of perovskite and value of tolerance factor $t$.

heterovalent $\mathrm{Pb}$ substitution in metal lead-based perovskites, as well as the replacement of the A and X sites. ${ }^{27,46}$ Therefore, the Goldschmidt substitution rule can be used to predict novel

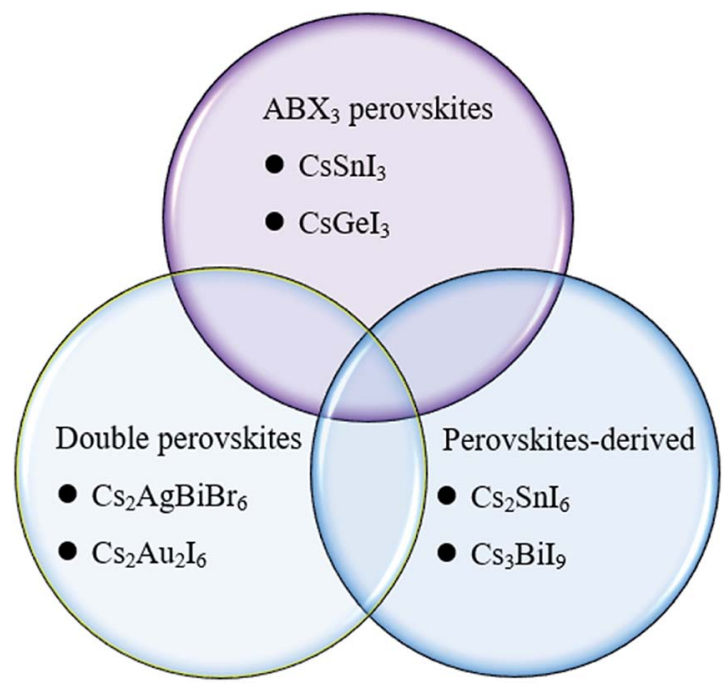

Fig. 5 Classification of inorganic lead-free perovskites for PV application. inorganic lead-free perovskite materials. According to the crystal structure of inorganic lead-free perovskites currently being studied, we classify inorganic lead-free perovskite materials into three categories: $\mathrm{ABX}_{3}$ perovskite, $\mathrm{A}_{2} \mathrm{~B}^{1+} \mathrm{B}^{3+} \mathrm{X}_{6}$ double perovskite and perovskite-derived materials (Fig. 5). This review will also elaborate on the research progress of various inorganic lead-free perovskite solar cells from these three categories, and the future solutions to existing problems.

\section{3. $\mathrm{ABX}_{3}$ perovskites}

\section{1 $\mathrm{CsSnI}_{3}$ perovskite material}

$\mathrm{Sn}$ and $\mathrm{Pb}$ are in the same main family and have similar electronic arrangements. Kanatzidis et al. first synthesized $\mathrm{Sn}-\mathrm{Pb}$ mixed doped perovskite solar cells and optimized the band gap width of the material by changing the ratio of $\mathrm{Sn}$ and $\mathrm{Pb}^{.77}$ Their study showed that $\mathrm{Sn}$ is a complete potential replacement for $\mathrm{Pb}$ as the light absorbing the material. Subsequently, further investigations were conducted using $\mathrm{Sn}$ as a substitute for $\mathrm{Pb}$ in perovskite solar cells, where $\mathrm{CsSnI}_{3}$ is a distinctive perovskite material. ${ }^{48,49} \mathrm{In}$ fact, $\mathrm{CsSnI}_{3}$ is not a brand-new material since an early study on the structural information of $\mathrm{CsSnI}_{3}$ compounds in powder for was initially reported by Scaife $e t a l$. in 1974. Ten years later, Mauersberger and Huber synthesized a yellow needle-like $\mathrm{CsSnI}_{3}$ crystallite, and its crystal structure was independently identified. ${ }^{50}$ Additional information was even provided before Yamada $e t$ al. discovered another polymorph of this compound in 1991. This polymorph was named black $\mathrm{CsSnI}_{3}$ due to its glossy black color. ${ }^{50} \mathrm{CsSnI}_{3}$ is a unique phasechange material that exhibits two polymorphs at room temperature: one has a one-dimensional yellow double-chain structure $\left(\mathrm{Y}^{-\mathrm{CsSnI}_{3}}\right)$ and the other one a three-dimensional black perovskite structure (B- $\left.\gamma-\mathrm{CsSnI}_{3}\right)$ (Fig. 6). ${ }^{51}$

The $\mathrm{B}-\gamma-\mathrm{CsSnI}_{3}$ perovskite has a photoelectric response, while the $\mathrm{Y}^{-} \mathrm{CsSnI}_{3}$ perovskite does not. Therefore, most studies have been generally focused on the application of B- $\gamma-\mathrm{CsSnI}_{3}$ perovskite. B- $\gamma-\mathrm{CsSnI}_{3}$ possesses a band gap of $1.3 \mathrm{eV}$ with a corresponding spectral response extending to $950 \mathrm{~nm}$ and low exciton binding energy (10-20 meV). The latter implies that only a small driving force is needed to separate most photogenerated carriers into free carriers..$^{52}$ 
a)

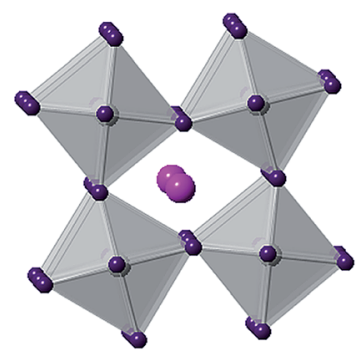

b)

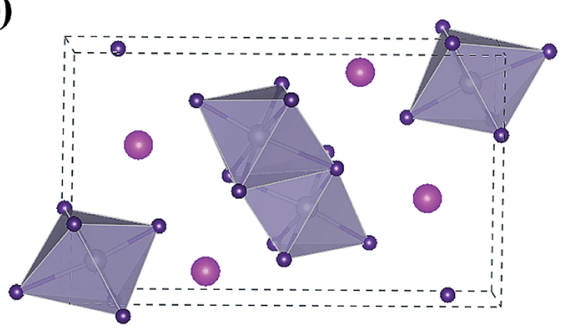

Fig. 6 (a) Crystal structure of $\mathrm{B}-\gamma-\mathrm{CsSnl}{ }_{3}$. $\mathrm{B}$ (b) Crystal structure of $\mathrm{Y}-\mathrm{CsSnl} \mathrm{z}_{3}$. In these two images, the magenta spheres represent the $\mathrm{Cs}$ atoms, the purple spheres represent the I atoms, and the gray spheres represent the $\mathrm{Sn}$ atoms.

These superior properties are particularly fascinating for solar cell application. In 2012, Chen et al. described a Schottky solar cell based on $\mathrm{B}-\gamma$-CsSnI 3 , which was fabricated via a vacuum-based technique. The solar cell consisted of a simple structure of indium tin oxide (ITO)/CsSnI $/ 3 / \mathrm{Au} / \mathrm{Ti} .{ }^{53}$ However, the $\mathrm{CsSnI}_{3}$ material is easily oxidized in air. The first article for this material showed a PCE of only $0.9 \%$. B- $\gamma$ - $\mathrm{CsSnI}_{3}$ is a p-type direct band gap semiconductor with a carrier concentration of $10^{17} \mathrm{~cm}^{-3}$ and hole mobility of $585 \mathrm{~cm}^{2} \mathrm{~V}^{-1} \mathrm{~s}^{-1} .{ }^{51}$ Even though $\mathrm{B}-\gamma-\mathrm{CsSnI}_{3}$ is a semiconductor, it is prone to inherent defects associated with Sn vacancies. ${ }^{51}$ Thus, it is critical to control the inherent defect concentration to optimize the B- $\gamma$-CsSnI ${ }_{3}$-based device. For instance, Sn-rich growth conditions can tune the hole carrier concentration to a medium level. Conversely, excessive $\mathrm{Sn}$ can occupy the I sites and $\mathrm{Sn}_{\mathrm{I}}$ antisite defects, and hence act as recombination centers. ${ }^{52}$ Briefly, moderate Sn-rich conditions are beneficial to improve the performance of $\mathrm{B}-\gamma$ $\mathrm{CsSnI}_{3}$-based devices. Accordingly, it is inevitable to reduce the inherent defects caused by Sn vacancies to apply the B- $\gamma-\mathrm{CsSnI}_{3}$ material in solar cell devices. ${ }^{54}$ These defects can be effectively suppressed via the method of Sn compensation by adding additional Sn-containing compounds $\left(\mathrm{SnF}_{2}, \mathrm{SnI}_{2}\right.$, and $\left.\mathrm{SnCl}_{2}\right)$. These three compounds can effectively inhibit Sn vacancies in the $\mathrm{B}-\gamma-\mathrm{CsSnI}_{3}$ material. Although $\mathrm{SnF}_{2}$ is more chemically stable than the other two compounds, it easily forms a separate phase in $\mathrm{CsSnI}_{3}$ films. ${ }^{52} \mathrm{SnI}_{2}$ has the best dispersibility in the $\mathrm{CsSnI}_{3}$ precursor solution, but the corresponding device stability is low. ${ }^{55}$ Compared with the other compounds $\left(\mathrm{SnF}_{2}\right.$ and $\mathrm{SnI}_{2}$ ), $\mathrm{SnCl}_{2}$ can significantly improve the stability of $\mathrm{CsSnI}_{3}$ devices. ${ }^{56}$

3.1.1 Sn compensation: $\mathbf{S n F}_{2}$. The most chemically stable Sn-containing compound is $\mathrm{SnF}_{2}$. Kumar et al. demonstrated that by adding a small amount of $\mathrm{SnF}_{2}$, the device performance can be significantly enhanced. ${ }^{54}$ In detail, a precursor solution was dissolved in DMSO by dissolving a suitable ratio of CsI, $\mathrm{SnI}_{2}$ and $\mathrm{SnF}_{2}$ powder. The film was then prepared by spin coating and annealed at $70{ }^{\circ} \mathrm{C}$. The device with the structure of FTO/ compact $\mathrm{TiO}_{2} \quad\left(\mathrm{c}-\mathrm{TiO}_{2}\right) /$ mesoporous $^{\mathrm{TiO}_{2}} \quad\left(\mathrm{~m}-\mathrm{TiO}_{2}\right) / \mathrm{CsSnI}_{3} /$ spiro-OMeTAD/Au exhibited a $J_{\mathrm{SC}}$ of $22.70 \mathrm{~mA} \mathrm{~cm}{ }^{-2}, V_{\mathrm{OC}}$ of $0.24 \mathrm{~V}$, and FF of 0.37 , achieving a PCE of $2.02 \% .{ }^{54}$ Consequently, the addition of $\mathrm{SnF}_{2}$ to $\mathrm{CsSnI}_{3}$ is critical in attaining photovoltaic performance through the reduction of Sn vacancies and concentration of these defects. By comparing the effects of $\mathrm{SnF}_{2}$ on solar cell performance, it was found that it can indeed suppress Sn vacancies and reduce hole carrier concentration, thereby avoiding the appearance of the yellow phase. However, we should note that although the device exhibited good photocurrent, the output voltage and fill factor values are relatively lower than that of $\mathrm{Pb}$-based perovskites.

3.1.2 Sn compensation: $\mathrm{SnI}_{2} \cdot \mathrm{SnF}_{2}$ is chemically stable, which indicates it easily forms a separate phase in perovskite films. ${ }^{55}$ The dispersibility of $\mathrm{SnI}_{2}$ in the precursor solution is higher than that of $\mathrm{SnF}_{2}$, and the addition of $\mathrm{SnI}_{2}$ leaves an undetectable effect on phase separation in the perovskite film. Therefore, researchers have begun to investigate the use of excess $\mathrm{SnI}_{2}$ as an Sn compensator for the growth of perovskite films. ${ }^{5,57}$ Marshall et al. first examined the effect of $\mathrm{SnI}_{2}$ in perovskite films. ${ }^{57}$ The device with the structure of ITO/CuI/ $\mathrm{CsSnI}_{3} /$ fullerene/bathocuproine (BCP)/Al exhibited a high $V_{\mathrm{OC}}$ of $0.55 \mathrm{~V}$ with an efficiency of $2.78 \%$. Although the efficiency was relatively low, this high $V_{\mathrm{OC}}$ has inspired researchers to choose an appropriate transport layer for pursuing a higher $V_{\mathrm{OC}}$ in $\mathrm{CsSnI}_{3}$ devices. Rather than adding $\mathrm{SnI}_{2}$ as an Sn compensator in the precursor solution, Song et al. used a novel reducing vapor atmosphere method (hydrazine as the vapor) to improve the quality of the perovskite film..$^{55,58}$ The hydrazine solution (50 $\mu \mathrm{L})$ was added to the spin-coating instrument in a glove box to create a reducing vapor atmosphere to prepare the film. Hydrazine not only effectively inhibited the formation of highly oxidized $\mathrm{Sn}^{4+}$ during film preparation, thereby reducing $\mathrm{Sn}$ vacancies, but also increased the carrier lifetime and reduced recombination..$^{55}$ Although hydrazine is also a strong reducing agent, its high volatility results in it is easy removal instead of depositing on the perovskite film like $\mathrm{SnF}_{2}$. With determination, the device achieved appreciated $\mathrm{PV}$ parameters of $V_{\mathrm{OC}}=$ $382 \mathrm{mV}, J_{\mathrm{SC}}=25.71 \mathrm{~mA} \mathrm{~cm}{ }^{-2}, \mathrm{FF}=0.49, \eta=4.81 \%{ }^{55}$ This is the highest efficiency for $\mathrm{CsSnI}_{3}$ PSCs reported to date. Nonetheless, the stability of the device is still poor, which is reflected by a great reduction in device efficiency after exposure for a few hours in air. It is also worth noting that hydrazine vapor is highly toxic and explodes at high temperature. Thus, this method is unsuitable for the manufacturing of solar cells.

3.1.3 Sn compensation: $\mathbf{S n C l}_{2}$. The spontaneous conversion of $\mathrm{B}-\gamma-\mathrm{CsSnI}_{3}$ to $\mathrm{Y}^{-\mathrm{CsSnI}_{3}}$ under humid air conditions results in poor device stability. However, increasing the stability of B- $\gamma-\mathrm{CsSnI}_{3}$ PSCs remains an unfortunate and unavoidable challenge. Marshall et al. studied the effects of $\mathrm{SnF}_{2}, \mathrm{SnCl}_{2}$, $\mathrm{SnBr}_{2}$, and $\mathrm{SnI}_{2}$ additives on the stability of $\mathrm{CsSnI}_{3}$ films. ${ }^{56}$ They 
monitored the absorption of the films under air conditions to determine suitable additives for film stability. The results revealed that the addition of $\mathrm{SnCl}_{2}$ resulted in a film with significantly higher stability than the other additives. ${ }^{56}$ The devices using the structure of ITO/CsSnI $3+10 \mathrm{~mol} \% \mathrm{SnCl}_{2} /$ phenyl- $\mathrm{C}_{61}$-butyric acid methyl ester $\left(\mathrm{PC}_{61} \mathrm{BM}\right) / \mathrm{BCP} / \mathrm{Al}$ exhibited a PCE of $3.56 \%$. Importantly, the addition of $\mathrm{SnCl}_{2}$ and the removal of the HTL significantly improved the stability of the device. The addition of $\mathrm{SnCl}_{2}$ hindered the oxidation on the surface of the perovskite film by air and water, thereby improving the device stability. Even if $\mathrm{SnCl}_{2}$ is oxidized, the formed stable hydrate can also alleviate the oxidation of $\mathrm{CsSnI}_{3} \cdot{ }^{56} \mathrm{Comparing}$ the $\mathrm{CsSnI}_{3}$-based PSCs to the $\mathrm{CsPbI}_{3}$-based PSCs with the same device structure, the stability lifetime of the latter was only one-tenth of the former. This was the first report in which the stability of the Sn-based PSCs was higher than that of the Pb-based PSCs.

3.1.4 Without tin additives. The above-mentioned B- $\gamma$ $\mathrm{CsSnI}_{3}$ films with Sn-containing additive were annealed below $100{ }^{\circ} \mathrm{C}$, which causes poor film quality and limits the device performance. Wang et al. considered optimizing the film morphology from the preparation process to increase the grain size, thereby reducing the grain boundary and improving the stability and performance of the device..$^{59} \mathrm{~A}$ mixed solution of acetone and DMF was used to dissolve the $\mathrm{B}-\gamma-\mathrm{CsSnI}_{3}$ raw material obtained by melting $\mathrm{CsI}$ and $\mathrm{SnI}_{2}$ in evacuated tubes. The precursor solution was then deposited on the substrate by spin coating and annealed at different temperatures $\left(100{ }^{\circ} \mathrm{C}\right.$, $150{ }^{\circ} \mathrm{C}, 200^{\circ} \mathrm{C}, 250^{\circ} \mathrm{C}$ and $300^{\circ} \mathrm{C}$ ). The grain size became larger as the annealing temperature increased and the reducing grain boundary increased the stability of the device to air and water. ${ }^{59}$ The film quality was found to deteriorate with the appearance of some small holes at higher temperatures (exceeding $200{ }^{\circ} \mathrm{C}$ ), which reduced the carrier lifetime and increase the film roughness, resulting in a declining interface contact. The film exhibited the best coverage at an annealing temperature of $150{ }^{\circ} \mathrm{C}$ with a grain size of about $300 \mathrm{~nm}$. Spiro-OMeTAD needs to be doped to increase its hole conductivity; however, the oxidation process for doping spiro-OMeTAD leads to the degradation of the B- $\gamma$-CsSnI 3 phase. To overcome the drawbacks of spiro-OMeTAD, an inverted structure device using $\mathrm{NiO}_{x}$ as the HTL was adopted. The device displayed a $V_{\mathrm{OC}}$ of $0.52 \mathrm{~V}$, $J_{\mathrm{SC}}$ of $10.21 \mathrm{~mA} \mathrm{~cm}{ }^{-2}$, FF of 0.625 , and PCE of $3.31 \%{ }^{59}$

\section{2 $\mathrm{CsSnI}_{3-x} \mathrm{Br}_{x}$-based perovskite solar cells}

Although $\mathrm{CsSnI}_{3}$ PSCs have high photocurrent, their efficiency is limited by their low $V_{\mathrm{OC}}$. The substitution of $\mathrm{Br}$ for I can increase the band gap of the perovskite material and hence improve the device $V_{\mathrm{OC}}{ }^{60}$ For instance, by modulating the $\mathrm{Br}$ content, the band gaps for $\mathrm{CsSnI}_{3}, \mathrm{CsSnI}_{2} \mathrm{Br}, \mathrm{CsSnIBr}_{2}$, and $\mathrm{CsSnBr}_{3}$ were determined to be $1.27 \mathrm{eV}, 1.37 \mathrm{eV}, 1.65 \mathrm{eV}$ and $1.75 \mathrm{eV}$, respectively. The addition of $\mathrm{Br}$ also increased the device $V_{\mathrm{OC}}{ }^{60}$ The $V_{\mathrm{OC}}$ improvement is ascribed to the reduced background of the carrier density by several orders of magnitude relative to $\mathrm{CsSnI}_{3}$ and increased charge recombination resistance when I is gradually replaced by $\mathrm{Br}$. However, this increase in $V_{\mathrm{OC}}$ was obtained at the expense of the photocurrent. Thus, the primary task of further optimizing the device performance using this type of material is to increase the photocurrent. It was reported that the incorporation of $\mathrm{Br}$ in the organic-inorganic halide perovskite $\left(\mathrm{MAPbI}_{3}\right)$ improved the stability of the device; whereas, the incorporation of $\mathrm{Br}$ in the $\mathrm{CsSnI}_{3}$ perovskite material had a minor effect on its stability. ${ }^{60}$ The chemical instability of $\mathrm{CsSnI}_{3-x} \mathrm{Br}_{x}$ is due to the tendency of $\mathrm{Sn}^{2+}$ to be oxidized to $\mathrm{Sn}^{4+}$. Thus, suppressing $\mathrm{Sn}$ vacancies and reducing the formation of $\mathrm{Sn}^{4+}$ are necessary to improve the device performance. By adding a reductive additive, the precursor can be effectively stabilized while reducing the $\mathrm{Sn}$ vacancy concentration and also suppressing charge recombination. ${ }^{61}$ Similarly to the process of preparing $\mathrm{CsSnIBr}_{2}$ films, adding hypophosphorous acid (HPA) can inhibit the formation of Sn vacancies. HPA possesses a P-O bond, which can strongly coordinate with $\mathrm{Sn}^{2+}$ to stabilize $\mathrm{CsSnIBr}_{2}$ compounds. Furthermore, HPA is a reducing agent, which prevents the oxidation of $\mathrm{Sn}^{2+}{ }^{21}$ The device demonstrated an improved PCE when the $\mathrm{CsSnIBr}_{2}$ solution with HPA was embedded in the $\mathrm{TiO}_{2} / \mathrm{Al}_{2} \mathrm{O}_{3} / \mathrm{C}$ structure, which enhanced the device performance with a $V_{\mathrm{OC}}$ of $0.31 \mathrm{~V}, J_{\mathrm{SC}}$ of $17.4 \mathrm{~mA} \mathrm{~cm}{ }^{-2}$, FF of 0.56 and PCE of $3.2 \%$. The efficiency of the device with HPA was twice of that without HPA. More importantly, the prepared $\mathrm{CsSnIBr}_{2}$ PSCs exhibited stable device performances for a period of 77 days under atmospheric conditions. When tested at $473 \mathrm{~K}$ for $9 \mathrm{~h}$, the device still retained $98 \%$ of its initial value, indicating that the device has great thermal stability. ${ }^{61}$ Gupta $e t$ al. preheated the $\mathrm{CsSnBr}_{3}$ precursor solution and substrate at $75{ }^{\circ} \mathrm{C}$ and $100{ }^{\circ} \mathrm{C}$, respectively, to produce a high-quality film via a one-step method. The optimal $\mathrm{CsSnBr}_{3}$ PSCs exhibited a PCE of $2.1 \%$, with a $J_{\mathrm{SC}}$ of $9 \mathrm{~mA} \mathrm{~cm}{ }^{-2}, V_{\mathrm{OC}}$ of $0.41 \mathrm{~V}$, and FF of $58 \% .^{62}$

\section{3 $\mathrm{ASnX}_{3}$ with varying inorganic cations at the A site}

The $V_{\mathrm{OC}}$ of $\mathrm{CsSnI}_{3}$-based devices is essentially limited by the small ionization potential ( $\mathrm{I}_{\mathrm{P}}$, approximately $4.9 \mathrm{eV}$ ) of the $\mathrm{CsSnI}_{3}$ material, which is only half that of Pb-based perovskite. ${ }^{63}$ Substitution of $\mathrm{Br}$ with $\mathrm{I}$ in the $\mathrm{CsSnI}_{3}$ perovskite material can increase its $I_{P}$ and band gap, resulting in an increase in the device $V_{\mathrm{OC}}$. By replacing the Cs cation at the A site with the smaller-sized $\mathrm{Rb}$ cation to form $\mathrm{Cs}_{1-x} \mathrm{Rb}_{x} \mathrm{SnI}_{3},{ }^{64}$ the $\mathrm{I}_{\mathrm{P}}$ of the material increased to $5.45 \mathrm{eV}^{63}$ It was found that the $\mathrm{Cs}_{0.8^{-}}$ $\mathrm{Rb}_{0.2} \mathrm{SnI}_{3}$ PSCs exhibited the best device efficiency of $2.64 \%$. For a low substitution level $(x=0.2)$, the $V_{\mathrm{OC}}$ of the $\mathrm{Cs}_{0.8} \mathrm{Rb}_{0.2} \mathrm{SnI}_{3}$ PSCs $(0.48 \mathrm{~V})$ increased by $120 \mathrm{meV}$ relative to that of pure $\mathrm{CsSnI}_{3}(0.36 \mathrm{~V})$, which generally resulted in an increased $\mathrm{I}_{\mathrm{P}}$ for the perovskite material with the incorporation of $\mathrm{Rb}$. It is worth noting that the band gap of $\mathrm{Cs}_{0.8} \mathrm{Rb}_{0.2} \mathrm{SnI}_{3}(1.33 \mathrm{eV})$ was only increased by $30 \mathrm{meV}$ relative to that of pure $\mathrm{CsSnI}_{3}$, which means the small amount of Rb substitution did not substantially reduce the wavelength range of light absorption. However, a further increase in the $\mathrm{Rb}$ content $(x>0.5)$ can easily cause $\mathrm{SnI}_{6}$ octahedral lattice distortion and strain, which lead to a decrease in stability. ${ }^{63}$ The band gap distribution obtained with first-principles DFT calculations over approximately 260 species of inorganic lead-free perovskites further suggests that 
cubic- $\mathrm{KSnCl}_{3}$ and cubic-RbSnCl${ }_{3}$ with ideal band gaps (1.24$1.44 \mathrm{eV}$ ) may be potential replacements for Pb-based perovskites. ${ }^{65}$ Thus, it is worth exploring the photoelectric properties of both materials in the future.

\subsection{Ge-based perovskite}

Lead $(\mathrm{Pb})$ can be replaced by germanium (Ge), for instance, to avoid toxicity and incorporate cesium to strengthen the stability. Ge, which is from the IVA family, is widely used as a dopant to create tailored semiconductor properties by mixing with proper amounts of other elements. ${ }^{66}$ Compared to Sn and $\mathrm{Pb}$, Ge has a stronger tendency to form $\mathrm{sp}^{3}$ hybrids and let both $\mathrm{s}$ and $\mathrm{p}$ electrons join in the bonding. When incorporated into perovskites, there is a strong tendency for Ge to move offcenter along the diagonal in its octahedral surroundings, resulting in a stronger bonding to three of its halogen neighbors and causes intrinsic stability in perovskites. ${ }^{67}$ Experimentally, Ge-based halide perovskites with stable rhombohedral crystal structures have been synthesized, which do not show any phase changes in the working temperature range of the device. These compounds are stable up to $150{ }^{\circ} \mathrm{C}$. It is worth mentioning that Ge-based perovskites are a natural extension of the $\mathrm{ABX}_{3}$ family of materials, which still preserve the same basic band structures and suitable band gaps for solar cells. The band gaps of different halide elements (Cl, Br, and I), $\mathrm{CsGeCl}_{3}, \mathrm{CsGeBr}_{3}$, and $\mathrm{CsGeI}_{3}$ were calculated to be $3.67 \mathrm{eV}, 2.32 \mathrm{eV}$ and $1.53 \mathrm{eV}$, respectively. ${ }^{66}$ Therefore, $\mathrm{CsGeI}_{3}$ is more appealing to researchers than the other two. $\mathrm{CsGeI}_{3}$ has a three-dimensional (3D) perovskite structure accompanied by small rhombohedral distortion. Similar to $\mathrm{CsSnI}_{3}, \mathrm{CsGeI}_{3}$ is also easily oxidized to present a yellow phase in air. Compared with their Pb-based counterparts, tin and germanium-based perovskite compounds have stronger antibonding properties near the valence band maximum (VBM) due to their active $\mathrm{Sn} 5 \mathrm{~s}$ lone pair and Ge $4 \mathrm{~s}$ lone pair. This results in the sudden formation of holes at the VBM of the perovskite material, and as a consequence, brings the oxidization of $\mathrm{Sn}^{2+}$ / $\mathrm{Ge}^{2+}$ to $\mathrm{Sn}^{4+} / \mathrm{Ge}^{4+}$. Calculations on defect density have showed that $\mathrm{CsGeI}_{3}$ is a p-type semiconductor, ${ }^{66}$ which suggests that its hole density can be tuned by adjusting the chemical potential of its constituent elements. For instance, $\mathrm{CsGeI}_{3}$ grown under Gerich conditions is a semiconductor material with good conductivity and low hole density. Theoretically, this material can be used as a light absorbing material for solar cell application.
However, due to its strong short-range potential such as Ge-Ge covalent bonds, the $\mathrm{I}^{-}$defect in $\mathrm{CsGeI}_{3}$ acts as a deeper electron defect than that in $\mathrm{CsSnI}_{3}$ and $\mathrm{MAPbI}_{3}$, which significantly confines electron migration and thus affects the open circuit voltage of solar cells. ${ }^{66}$ Krishnamoorthy et al. selected DMF as a precursor solvent and used $\mathrm{TiO}_{2}$ and spiro-MeOTAD as ETL and $\mathrm{HTL}$, and initially reported solar cells based on $\mathrm{CsGeI}_{3}$ material. The solar cell had a low $V_{\text {OC }}$ of $74 \mathrm{mV}$ and PCE of only $0.11 \%{ }^{67}$ The reason for the low performance of the device was mainly due to the poor quality of the perovskite film and the poor air stability of the perovskite material, where $\mathrm{Ge}^{2+}$ is oxidized to $\mathrm{Ge}^{4+}$ during film formation and device fabrication. Thus, the poor air stability of $\mathrm{CsGeI}_{3}$ restricted the performance of the device. ${ }^{68}$ Therefore, increasing the air stability of $\mathrm{CsGeI}_{3}$ remains a challenge in the field of optoelectronics. Mixing tin with germanium to produce new perovskite materials can be a feasible strategy. DFT calculation has revealed that $\mathrm{RbSn}_{0.5} \mathrm{Ge}_{0.5} \mathrm{I}_{3}$ materials possess desirable band gaps (0.9-1.6 eV) with great light absorption, high carrier mobility, and better water, and thermal stability than organic-inorganic lead-based halide perovskites. Thus, this new inorganic lead-free perovskite material may provide a favorable direction for the development of Sn-based and Ge-based perovskite devices. ${ }^{69}$

A summary of the optical data and structures based on tin, germanium halide perovskites and their performances as absorbing materials in PV devices are given in Table 1.

\section{Double perovskite structured materials}

\subsection{Perovskites with the $\mathrm{A}_{2} \mathrm{~B}^{1+} \mathrm{B}^{3+} \mathrm{X}_{6}$ formula}

The double perovskite structure $\mathrm{A}_{2} \mathrm{~B}^{1+} \mathrm{B}^{3+} \mathrm{X}_{6}$ refers to the simultaneous replacement of the $\mathrm{A}$ and $\mathrm{B}$ positions by different elements, and in this manner a double perovskite material is alternately arranged by different octahedral structures (Fig. 7). ${ }^{\text {o }}$ Most double perovskite materials are more stable and environmentally friendly than the conventional organic-inorganic hybrid lead halide $\mathrm{ABX}_{3}$ perovskite materials. For instance, the decomposition energies of $\mathrm{Cs}_{2} \mathrm{AgBiCl}_{6}$ and $\mathrm{Cs}_{2} \mathrm{AgBiBr}_{6}$ are $0.57 \mathrm{eV}$ and $0.38 \mathrm{eV}$, respectively, which are higher than that of $\mathrm{MAPbI}_{3}(0.11-0.14 \mathrm{eV}) .^{71}$ This indicates that these double perovskite materials are more stable than conventional organic-inorganic hybrid lead halide $\mathrm{ABX}_{3}$ perovskite materials.

Table 1 Properties of tin and germanium perovskites and their device efficiencies

\begin{tabular}{|c|c|c|c|c|c|c|c|}
\hline Materials & $E_{\mathrm{g}}(\mathrm{eV})$ & $\mathrm{PL}(\mathrm{nm})$ & Crystal structure & HTL & ETL & $\mathrm{PCE} / \%$ & Ref. \\
\hline $\mathrm{CsSnI}_{3}$ with $\mathrm{SnF}_{2}$ & 1.27 & 976 & Orthorhombic & Spiro-OMeTAD & $\mathrm{TiO}_{2}$ & 2.02 & 54 \\
\hline $\mathrm{CsSnI}_{3}$ with $\mathrm{SnI}_{2}$ & & & & $\mathrm{CuI}$ & Fullerene & 2.78 & 57 \\
\hline $\mathrm{CsSnI}_{3}$ with $\mathrm{SnI}_{2}$ & & & & PTAA & $\mathrm{TiO}_{2}$ & 4.81 & 55 \\
\hline $\mathrm{CsSnI}_{3}$ with $\mathrm{SnCl}_{2}$ & & & & & PCBM & 3.56 & 58 \\
\hline $\mathrm{CsSnI}_{3}$ & & & & $\mathrm{NiO}$ & PCBM & 3.31 & 59 \\
\hline $\mathrm{CsSnI}_{2} \mathrm{Br}$ & 1.37 & 905 & Cubic & Spiro-OMeTAD & $\mathrm{TiO}_{2}$ & 1.67 & 60 \\
\hline $\mathrm{CsSnIBr}_{2}$ & 1.65 & 771 & Cubic & & $\mathrm{TiO}_{2}$ & 3.2 & 61 \\
\hline $\mathrm{CsSnBr}_{3}$ & 1.75 & 709 & Cubic & Spiro-OMeTAD & $\mathrm{TiO}_{2}$ & 2.1 & 62 \\
\hline $\mathrm{CsGeI}_{3}$ & 1.53 & 810 & Rhombohedral & Spiro-OMeTAD & $\mathrm{TiO}_{2}$ & 0.11 & 67 \\
\hline
\end{tabular}




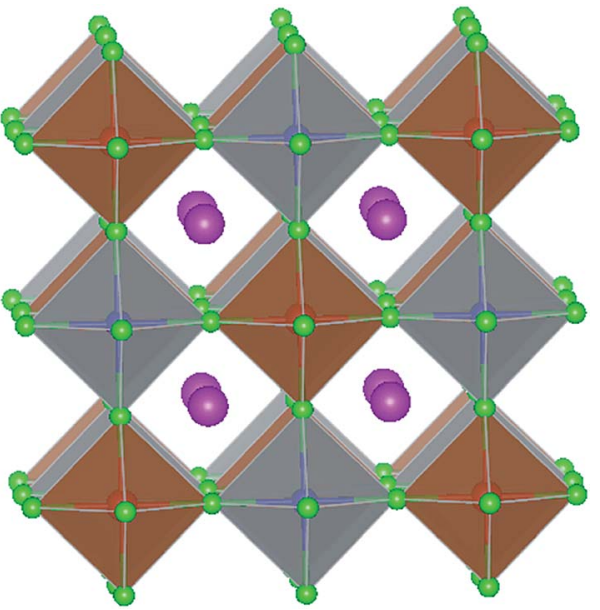

Fig. 7 Crystal structure of double perovskites. The magenta spheres represent $\mathrm{Cs}$ atoms, red spheres represent trivalent metal atoms (Bi and $\mathrm{Sb}$ atoms), blue spheres represent a monovalent metal atom ( $\mathrm{Ag}$ and $\mathrm{Cu}$ atoms), and green spheres represent a halogen atom $(\mathrm{Cl}$ and $\mathrm{Br}$ atom).

The Sn-based and Ge-based perovskite materials, which are homovalent substituted for $\mathrm{Pb}$ cations, severely restrain the indepth development of materials due to their poor air stability as discussed above. This situation can be improved by forming new inorganic lead-free perovskite materials via the heterovalent substitution of $\mathrm{Pb} .^{70}$ To initiate the heterovalent substitution of the $\mathrm{Pb}$ cation and maintain the material charge conserved, the B site must be occupied by a monovalent cation and a trivalent cation. $\mathrm{Bi}^{3+}$ has the same extra-core electron cloud configuration $\left(6 \mathrm{~s}^{2} 6 \mathrm{p}^{0}\right)$ as $\mathrm{Pb}^{2+}$, which holds potential for the replacement. The appropriate size of $\mathrm{Ag}^{+}$can be used to maintain material charge conservation and form an effective double perovskite structure due to tolerance factor limitations. The synthesized cubic $F m \overline{3} m$ double perovskite $\mathrm{Cs}_{2} \mathrm{AgBiBr}_{6}$ exhibited a basic photoluminescence (PL) lifetime of about 660 ns at room temperature. ${ }^{70}$ This long carrier lifetime indicates the scientific importance for further exploration in the field of optoelectronics. This indirect band semiconductor with an optical band gap of $1.95 \mathrm{eV}$ has significantly higher thermal and moisture stability than $\mathrm{MAPbI}_{3}$. Furthermore, the analogues of $\mathrm{Cs}_{2} \mathrm{AgBiBr}_{6}$ and $\mathrm{Cs}_{2} \mathrm{AgBiCl}_{6}$ have been successfully synthesized, showing an indirect band gap of $2.19 \mathrm{eV}$ and $2.77 \mathrm{eV}$, respectively. ${ }^{72}$ Although the band gap of $\mathrm{Cs}_{2} \mathrm{AgBiI}_{6}$ is lower than the former two materials, theoretical calculations specify that $\mathbf{C s}_{2}{ }^{-}$ $\mathrm{AgBiI}_{6}$ is thermodynamically unstable. The calculated decomposition energy of $\mathrm{Cs}_{2} \mathrm{AgBiI}_{6}$ is $-0.41 \mathrm{eV}$, which means that $\mathrm{Cs}_{2} \mathrm{AgBiI}_{6}$ spontaneously decomposes. ${ }^{71}$

Besides understanding their optoelectronic properties, the successful application of these materials in solar cells can be attractive to common readers. The first device using $\mathrm{Cs}_{2} \mathrm{AgBiBr}_{6}$ materials was reported by $\mathrm{Wu}$ et $a .^{73} \mathrm{Cs}_{2} \mathrm{AgBiBr}_{6}$ powder was dissolved in DMSO solvent to prepare a perovskite film by spincoating and annealing at different temperatures. It was found that the traditional thermal annealing method caused the $\mathrm{Cs}_{2}$ $\mathrm{AgBiBr}_{6}$ film to have poor coverage, and the corresponding devices showed a low PCE $(<0.1 \%)$. Subsequently, a low pressureassisted (LPA) method was adopted to prepare a dense and high coverage $\mathrm{Cs}_{2} \mathrm{AgBiBr}_{6}$ film. The device displayed a PCE of $1.44 \%$, $V_{\mathrm{OC}}$ of $1.04 \mathrm{~V}, J_{\mathrm{SC}}$ of $1.78 \mathrm{~mA} \mathrm{~cm}^{-2}$ and FF of $0.78 .{ }^{73}$ However, the current of the $\mathrm{Cs}_{2} \mathrm{Ag} \mathrm{BiBr}_{6}$ device was lower than that of $\mathrm{Pb}$-based perovskite, and thus, further increasing the current is the key to optimizing device efficiency. Gao et al. employed the anti-solvent strategy to prepare a $\mathrm{Cs}_{2} \mathrm{AgBiBr}_{6}$ film. The use of isopropanol (IPA) as an anti-solvent promoted grain nucleation and rapid crystallization to obtain a smooth and uniform $\mathrm{Cs}_{2} \mathrm{AgBiBr}_{6}$ film. The best device exhibited a PCE of $2.23 \%, V_{\mathrm{OC}}$ of $1.01 \mathrm{~V}, J_{\mathrm{SC}}$ of $3.19 \mathrm{~mA} \mathrm{~cm}^{-2}$, and FF of $69.2 \%$. The reason for the low efficiency may be due to the limited thickness of the $\mathrm{Cs}_{2} \mathrm{AgBiBr}_{6}$ film (only $250 \mathrm{~nm}$ ), which correlated with low solubility in DMSO (only 0.4 $\mathrm{M})$, thus restraining the photocurrent. Therefore, Greul et al. directly dissolved $\mathrm{AgBr}, \mathrm{CsBr}$ and $\mathrm{BiBr}_{3}$ powder in DMSO solvent to obtain a precursor solution having a maximum solubility of $0.6 \mathrm{M}^{74}$ The device performance was further improved to a PCE of $2.5 \%$ with a current of $3.6 \mathrm{~mA} \mathrm{~cm} \mathrm{~cm}^{-2}$ via two different heating steps for the preparation of the $\mathrm{Cs}_{2} \mathrm{AgBiBr}_{6}$ film, in which the hot precursor solution $\left(75^{\circ} \mathrm{C}\right)$ was spin-coated onto a pre-warmed substrate followed by heat treatment at $285{ }^{\circ} \mathrm{C}$ for 5 minutes to effectively improve film coverage. Although $\mathrm{Cs}_{2} \mathrm{AgBiBr}_{6} \mathrm{PSCs}$ exhibit extremely high stability, their device efficiency should be enhanced to meet market demand.

\subsection{Band gap engineering}

Double perovskite materials such as $\mathrm{Cs}_{2} \mathrm{AgBiBr}_{6}$ and $\mathrm{Cs}_{2} \mathrm{AgBiCl}_{6}$ are indirect semiconductors with large band gaps over $2.0 \mathrm{eV}$. In addition, the exciton binding energy of these materials (over 200 $\mathrm{meV}$ ) is much higher than that of $\mathrm{MAPbI}_{3}(25 \mathrm{meV}){ }^{73}$ These unfavorable factors constrain the further development of device performance. As a result, the band gap engineering of these materials and the search for new double perovskite materials have gained attention. For example, the band gap of $\mathrm{Cs}_{2} \mathrm{AgBiBr}_{6}$ can be tuned by a small amount of substitution of $\mathrm{Sb}$ and In for $\mathrm{Bi}^{75}$ The different atomic structures of $\mathrm{Sb}$ and In can induce the change in band gap of these perovskite material. The addition of In increases the band gap of $\mathrm{Cs}_{2} \mathrm{AgBiBr}_{6}$, while the addition of $\mathrm{Sb}$ decreases the band gap. $\mathrm{Cs}_{2} \mathrm{Ag}\left(\mathrm{Bi}_{0.625} \mathrm{Sb}_{0.375}\right) \mathrm{Br}_{6}$ possessed a suitable band gap value of $1.86 \mathrm{eV} .^{75}$ Moreover, partially substituting $\mathrm{Ag}$ with $\mathrm{Cu}$ in $\mathrm{Cs}_{2} \mathrm{BiAgBr}_{6}$ can efficiently reduce the band gap of $\mathrm{Cs}_{2} \mathrm{BiAgBr}_{6}$. $\mathrm{Cs}_{2} \mathrm{BiAg}_{1-x} \mathrm{Cu}_{x} \mathrm{Cl}_{6}$ possessed a band gap of 1.6-1.9 eV with good stability. ${ }^{33}$ In addition to the partial substitution of $\mathrm{Ag}$ and $\mathrm{Bi}$ elements to modulate the band gap of the $\mathrm{Cs}_{2} \mathrm{AgBiBr}_{6}$ material, a direct band gap of $1.57 \mathrm{eV}$ was obtained for $\mathrm{Cs}_{2} \mathrm{AgBiBr}_{6}$ by adding $0.075 \% \mathrm{Tl}$ to modify the band edge of $\mathrm{Cs}_{2} \mathrm{AgBiBr}_{6} \cdot{ }^{75}$ However, interestingly, to date, there are no reports on the use of these materials for solar cell application.

Likewise, the deployment of new double perovskite materials has become the focus of researchers. Recently, the photoelectric properties of $\mathrm{Cs}_{2} \mathrm{Au}_{2} \mathrm{I}_{6}$ have been under comprehensive investigation. DFT calculation has shown that the charge disproportionation on $\mathrm{Au}$ makes the two $\mathrm{Au}$ atoms have a valence of +1 and +3 , which results in $\mathrm{Cs}_{2} \mathrm{Au}_{2} \mathrm{I}_{6}$ being a double perovskite material. ${ }^{76}$ This raises a different type of material from the 
previous $\mathrm{ABX}_{3}$-structured perovskites. By first-principles calculation, the band gap of $\mathrm{Cs}_{2} \mathrm{Au}_{2} \mathrm{I}_{6}$ was estimated to be $1.31 \mathrm{eV}$, which is close to the optimal value for PV materials suggested by the Shockley-Queisser theory. In addition, unlike the previously discussed double perovskite materials, $\mathrm{Cs}_{2} \mathrm{Au}_{2} \mathrm{I}_{6}$ is a direct band gap semiconductor. Debbichi et al. optically simulated the suitability of $\mathrm{Cs}_{2} \mathrm{Au}_{2} \mathrm{I}_{6}$ in a PV device with the structure of ITO/ $\mathrm{TiO}_{2} /$ perovskite layer/spiro-OMeTAD/Au. ${ }^{77}$ The results specified that the $\mathrm{Cs}_{2} \mathrm{Au}_{2} \mathrm{I}_{6}$-based device can deliver a PCE of $18.2 \%$ with $J_{\mathrm{SC}}$ of $25 \mathrm{~mA} \mathrm{~cm}{ }^{-2}$ even with a perovskite layer of around $50 \mathrm{~nm}$. Theoretical studies have shown that the highest $J_{\mathrm{SC}}$ of $\mathrm{Cs}_{2} \mathrm{Au}_{2} \mathrm{I}_{6}$ devices can even exceed $30 \mathrm{~mA} \mathrm{~cm} \mathrm{~cm}^{-2}$, thus exceeding a PCE of $20 \%$. This is comparable to the most popular Pb-based PSCs. In conclusion, $\mathrm{Cs}_{2} \mathrm{Au}_{2} \mathrm{I}_{6}$-based PSCs hold the potential for a big event in the development of perovskite.

\section{3 $\quad \mathrm{AA}^{\prime} \mathbf{B}_{2} \mathrm{X}_{6}$ perovskite}

In addition to the common replacement of $\mathrm{Cs}^{+}$at the A position of most double perovskite materials, co-doping of $\mathrm{Rb}^{+}$and $\mathrm{Cs}^{+}$ is captivating due to their similar chemical activity. ${ }^{78}$ In 2016, Gou et al. obtained the $(\mathrm{CsRb})_{2} \mathrm{Sn}_{2} \mathrm{I}_{6}$ double perovskite structure material by doping $\mathrm{Rb}$ in $\mathrm{CsSnI}_{3}$ to allow $\mathrm{Rb}$ and Cs to occupy the A position in the perovskite material. Although the bandgap of this material $\left(E_{\mathrm{g}}=1.58 \mathrm{eV}\right)$ is larger than the band gap of $\mathrm{CsSnI}_{3}$, studies have shown that the carrier effective mass of this double perovskite material is comparable to that of the $\mathrm{CsSnI}_{3}$ material. More importantly, the (CsRb) $\mathrm{Sn}_{2} \mathrm{I}_{6}$ material has ferroelectricity and can promote the separation of photogenerated carriers due to the coupling of the rotation and polarization misalignment of the $\left[\mathrm{SnI}_{6}\right]$ octahedron, forming a new type of ferroelectric PV with potentially enhanced PCE. ${ }^{78}$

\section{Perovskite-derived materials}

\section{$5.1 \quad \mathrm{~A}_{2} \mathrm{BX}_{6}$ formula}

With detailed studies of perovskite materials widely used in optoelectronic devices, a series of similar materials to perovskite have slowly been revealed. In addition to the abovementioned $\mathrm{ABX}_{3}$ and $\mathrm{A}_{2} \mathrm{~B}^{1+} \mathrm{B}^{3+} \mathrm{X}_{6}$ inorganic perovskite materials, inorganic lead-free perovskite-derived materials have acquired increasing attention in the past two years.

$\mathrm{Cs}_{2} \mathrm{SnI}_{6}$ is a lead-free perovskite-derived material with $\mathrm{Sn}$ defects. ${ }^{79} \mathrm{Cs}_{2} \mathrm{SnI}_{6}$ films can be directly obtained via a two-step deposition method. The material has a band gap of only $1.6 \mathrm{eV}$ and carrier density of $10^{16} \mathrm{~cm}^{-3}$, which was originally used as an HTL for dye-sensitized solar cell devices. ${ }^{\mathbf{8 0}} \mathrm{B}-\gamma-\mathrm{CsSnI}_{3}$ films prepared via the two-step method can be spontaneously oxidized to an air-stable $\mathrm{Cs}_{2} \mathrm{SnI}_{6}$ film in the external environment. ${ }^{81} \mathrm{Cs}_{2} \mathrm{SnI}_{6}$ is a defect variant of the $\mathrm{CsSnI}_{3}$ perovskite structure, and half of the octahedral Sn atoms are missing, resulting in isolated $\left[\mathrm{SnI}_{6}\right]^{2-}$ octahedra (Fig. 8). Due to the existence of $\mathrm{Sn}^{4+}$, the stability of $\mathrm{Cs}_{2} \mathrm{SnI}_{6}$ is significantly higher than that of $\mathrm{CsSnI}_{3}$. Furthermore, $\mathrm{Cs}_{2} \mathrm{SnI}_{6}$ has a direct band gap of $1.48 \mathrm{eV}$ and a high absorption coefficient (over $10^{5} \mathrm{~cm}^{-1}$ ), which is suitable for use as a light absorber. ${ }^{79}$ However, the first PSCs based on $\mathrm{Cs}_{2} \mathrm{SnI}_{6}$ materials in combination with $\mathrm{TiO}_{2}$ and P3HT as ETL and HTL showed a $V_{\text {OC }}$ and $J_{\text {SC }}$ of $0.51 \mathrm{~V}$ and 5.41 $\mathrm{mA} \mathrm{cm}^{-2}$, respectively, achieving a PCE of up to $0.96 \%{ }^{81}$ Although this efficiency was lower than that of lead-based perovskites, the device cell was stable in an air environment for more than one month. $\mathrm{Cs}_{2} \mathrm{SnI}_{6}$ only decomposes at a temperature of $250{ }^{\circ} \mathrm{C}$; therefore, in principle, this material possesses superior stability compared with the traditional perovskite materials. The many defects (iodine vacancy and tin interstitial) in $\mathrm{Cs}_{2} \mathrm{SnI}_{6}$ and its low electron mobility $\left(2.9 \mathrm{~cm}^{2} \mathrm{~V}^{-1}\right.$ $\mathrm{s}^{-1}$ ), as well as its large effective mass of holes, result in low PCE for devices with $\mathrm{Cs}_{2} \mathrm{SnI}_{6}$ as the light absorbing layer. ${ }^{79}$ The performance can be further improved by replacing $\mathrm{Br}$ with $\mathrm{I}$ in $\mathrm{Cs}_{2} \mathrm{SnI}_{6}$. A band gap tunable $\mathrm{Cs}_{2} \mathrm{SnI}_{6-x} \mathrm{Br}_{x}$ film (1.3-2.9 eV) was synthesized via a two-step method, ${ }^{82}$ and the best device based on the $\mathrm{Cs}_{2} \mathrm{SnI}_{4} \mathrm{Br}_{2}(x=2)$ material exhibited a PCE of $2.1 \%$. This was because the intrinsically deep defects of $\mathrm{Cs}_{2} \mathrm{SnI}_{6}$ narrowed the device performance.

Replacing the $\mathrm{Sn}^{4+}$ cation with transition metal cations can result in new perovskite materials, such as $\mathrm{Cs}_{2} \mathrm{PdBr}_{6} \cdot{ }^{83}$ The $\mathrm{Cs}_{2} \mathrm{PdBr}_{6}$ compound exhibits a band gap of $1.6 \mathrm{eV}$ and longlived photoluminescence. A simple "sandwich structure" device with ITO/ $\mathrm{Cs}_{2} \mathrm{PdBr}_{6} / \mathrm{Ag}$ was fabricated to evaluate whether $\mathrm{Cs}_{2} \mathrm{PdBr}_{6}$ had optoelectronic properties. The photo-response of the device indicated that this material may be suitable for use in

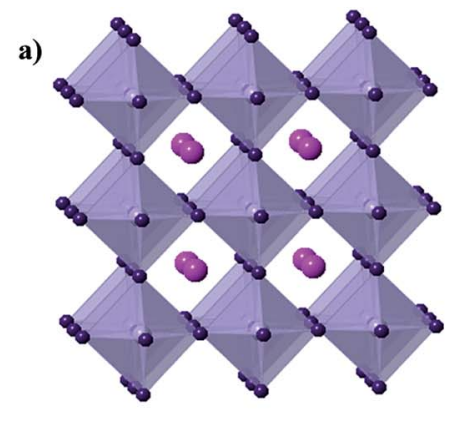

$\mathrm{CsSnI}_{3}$

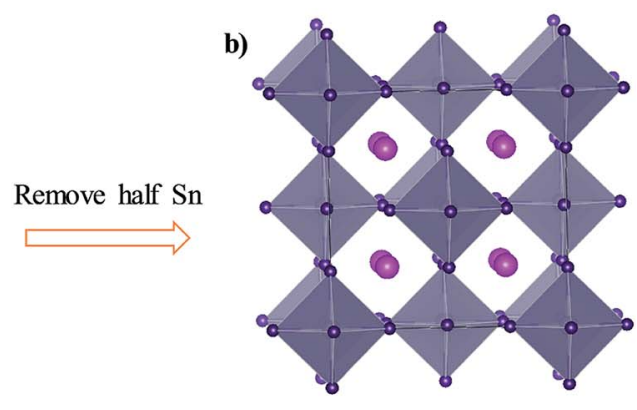

$\mathrm{Cs}_{2} \mathrm{SnI}_{6}$

Fig. 8 (a) Crystal structure of $\mathrm{CsSnl}_{3}$. (b) Crystal structure of $\mathrm{Cs}_{2} \mathrm{Snl}_{6}$. Consulting from ref. 79 
solar cells. A phase change and chemical decomposition were not observed when the $\mathrm{Cs}_{2} \mathrm{PdBr}_{6}$ crystal was placed in water for 10 minutes, indicating that this material has greater stability compared to lead-based perovskite materials. Similarly, the non-toxic Ti element can replace $\mathrm{Sn}$ to obtain novel perovskite materials such as $\mathrm{Cs}_{2} \mathrm{TiI}_{x} \mathrm{Br}_{6-x} \cdot{ }^{84} \mathrm{Cs}_{2} \mathrm{TiI}_{x} \mathrm{Br}_{6-x}$ materials were synthesized via the melt-crystallization method, and subsequent experimental measurement and theoretical computations showed that these materials had band gaps in the range of $1.0 \mathrm{eV}$ to $1.8 \mathrm{eV}$. Moreover, the $\mathrm{Cs}_{2} \mathrm{TiI}_{x} \mathrm{Br}_{6-x}$ materials have benign defect properties, excellent light absorption, and high stability. ${ }^{84}$ Thus, these materials are worth examining in the future. Chen et al. first reported $\mathrm{Cs}_{2} \mathrm{TiBr}_{6}$ PSCs and demonstrated experimentally the photoelectric effect of Ti-based perovskite materials. A $\mathrm{Cs}_{2} \mathrm{TiBr}_{6}$ film was prepared via a lowtemperature vapor method, a uniform $\mathrm{CsBr}$ film was first deposited on the substrate by thermal evaporation, and then the CsBr film was annealed in $\mathrm{a} \mathrm{TiBr}_{4}$ vapor atmosphere at $200{ }^{\circ} \mathrm{C}$. The $\mathrm{Cs}_{2} \mathrm{TiBr}_{6}$ film presented a band gap of $1.8 \mathrm{eV}$, electron and hole diffusion length exceeding $100 \mathrm{~nm}$, and excellent environmental stability. The device structure with $\mathrm{FTO} / \mathrm{TiO}_{2} / \mathrm{C}_{60} / \mathrm{Cs}_{2} \mathrm{TiBr}_{6} / \mathrm{P} 3 \mathrm{HT} / \mathrm{Au}$ was adopted to evaluate the PV performance of the $\mathrm{Cs}_{2} \mathrm{TiBr}_{6}$ material. The $\mathrm{C}_{60}$ layer was added to facilitate electron transfer from the $\mathrm{Cs}_{2} \mathrm{TiBr}_{6}$ layer to the $\mathrm{TiO}_{2}$ layer and modify the CsBr microstructure, yielding a uniform CsBr film. The device delivered a PCE of $3.3 \%$ with a $J_{\mathrm{SC}}$ of 5.69 $\mathrm{mA} \mathrm{cm}{ }^{-2}$ and $V_{\text {OC }}$ of $1.02 \mathrm{~V}$.

\section{$5.2 \quad \mathrm{~A}_{3} \mathrm{~B}_{2} \mathrm{X}_{9}$ formula}

$A_{3} B_{2} X_{9}$ is the structural formula of another representative class of perovskite-derived materials. Cs is usually used to occupy the position of $\mathrm{A}$, whereas $\mathrm{Bi}$ occupies the position of $\mathrm{B}$, which gives different crystal structures. Since $\mathrm{Bi}^{3+}$ and $\mathrm{Pb}^{2+}$ are in different valence states, it is impossible to directly replace $\mathrm{Pb}$ in perovskites to form $3 \mathrm{D}$ the $\mathrm{ABX}_{3}$ structure.$^{85}$ Therefore, the structure of Bi-based perovskite materials is different from that of $3 \mathrm{D} \mathrm{Pb}$ based perovskites, which have huge structural diversity of $0 \mathrm{D}$, $1 \mathrm{D}, 2 \mathrm{D}$, and $3 \mathrm{D}$ structures. The $\mathrm{Cs}_{3} \mathrm{Bi}_{2} \mathrm{I}_{9}$ material belongs to the OD structure and consists of bioctahedral $\left(\mathrm{Bi}_{2} \mathrm{I}_{9}\right)^{3-}$ clusters surrounded by $\mathrm{Cs}^{+}$cations (Fig. 9) ${ }^{\mathbf{8 6}}$ Park et al. first reported a $\mathrm{Cs}_{3} \mathrm{Bi}_{2} \mathrm{I}_{9}$ film obtained via a simple solution-processing method. The band gap of the $\mathrm{Cs}_{3} \mathrm{Bi}_{2} \mathrm{I}_{9}$ material is about $2.1 \mathrm{eV}$ (Table 2). The solar cells constructed with the structure of FTO/ m- $\mathrm{TiO}_{2} / \mathrm{Cs}_{3} \mathrm{Bi}_{2} \mathrm{I}_{9} /$ spiro-MeOTAD/Ag showed a PCE of $1.09 \%$, with a $V_{\mathrm{OC}}$ of $0.85 \mathrm{~V}$ and $J_{\mathrm{SC}}$ of $2.15 \mathrm{~mA} \mathrm{~cm}^{-2} .{ }^{85} \mathrm{DFT}$ calculations further revealed that $\mathrm{Cs}_{3} \mathrm{Bi}_{2} \mathrm{I}_{9}$ has a high carrier effective mass, large indirect band gap, and many deep defects. ${ }^{87}$ However, the devices based on the $\mathrm{Cs}_{3} \mathrm{Bi}_{2} \mathrm{I}_{9}$ material somehow displayed low PCE in many selected structures. ${ }^{88}$ This indicates that the $\mathrm{Cs}_{3} \mathrm{Bi}_{2} \mathrm{I}_{9}$ material may be unsuitable for solar cells applications. Nevertheless, $\mathrm{CsBi}_{3} \mathrm{I}_{10}$ films with a low band gap of $1.77 \mathrm{eV}$ were further synthesized via a solution method. ${ }^{89}$ The comparison of absorption curves revealed that $\mathrm{CsBi}_{3} \mathrm{I}_{10}$ had better light absorption than $\mathrm{Cs}_{3} \mathrm{Bi}_{2} \mathrm{I}_{9}$ with a cutoff edge at $700 \mathrm{~nm}$. Importantly, the layer structured $\mathrm{CsBi}_{3} \mathrm{I}_{10}$ can be fabricated into a dense and uniform film. The device with $\mathrm{CsBi}_{3} \mathrm{I}_{10}$ as the light

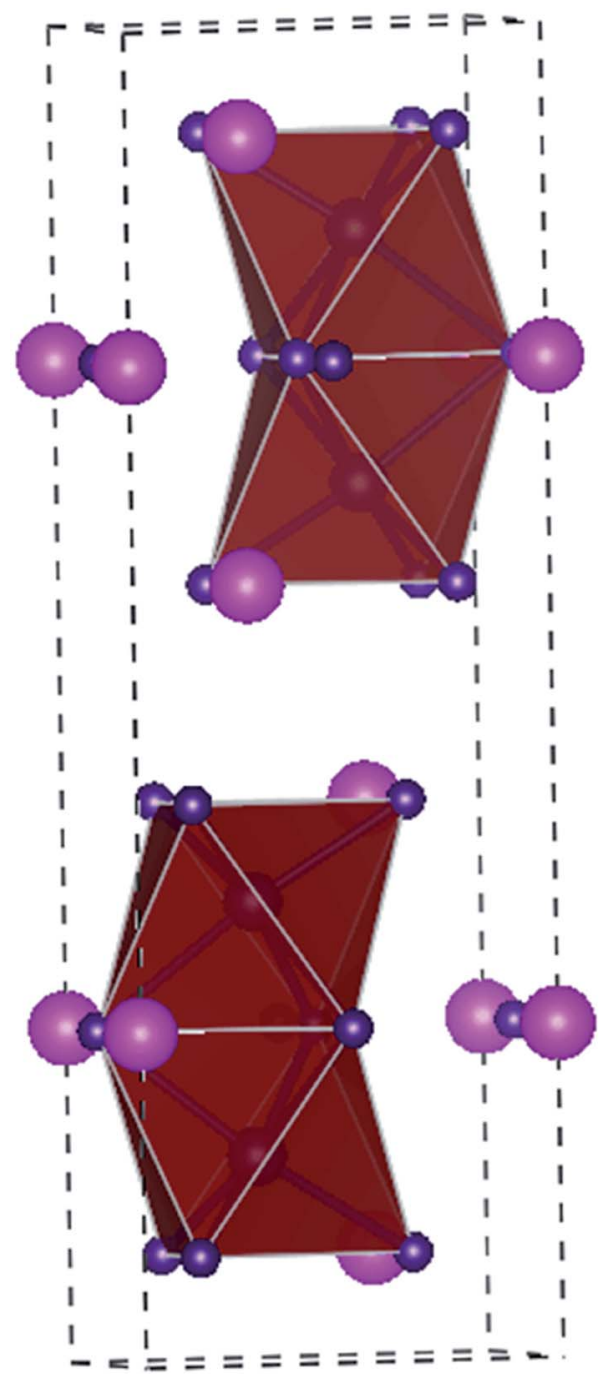

Fig. 9 Crystal structure of $A_{3} B_{2} l_{9}$ perovskites. The magenta spheres represent the $\mathrm{Cs}$ atoms, blue spheres represent the trivalent metal atom ( $\mathrm{Bi}, \mathrm{Sb}$ atom), and purple spheres represent the I atom.

absorbing material exhibited a PCE of $0.4 \%$, while the device with $\mathrm{Cs}_{3} \mathrm{Bi}_{2} \mathrm{I}_{9}$ as the light absorbing material under the same conditions had a PCE of only $0.02 \%$. Impressively, Shin et al. chose low-cost carbon as the electrode to fabricate the device of $\mathrm{FTO} / \mathrm{c}-\mathrm{TiO}_{2} / \mathrm{m}^{-\mathrm{TiO}_{2}} / \mathrm{CsBi}_{3} \mathrm{I}_{10} / \mathrm{ZrO}_{2} /$ carbon, showing a PCE of $1.51 \% .^{90}$ The device retained its performance when exposed to air for 30 days, indicating its excellent stability.

$\mathrm{Sb}$ and $\mathrm{Bi}$ have similar electronic configurations and can form $\mathrm{A}_{3} \mathrm{~B}_{2} \mathrm{X}_{9}$ structure perovskite compounds as well. ${ }^{91}$ Similar to Bi-based perovskites, Sb-based perovskite has the basic structure of $\mathrm{A}_{3} \mathrm{Sb}_{2} \mathrm{X}_{9}$ with a $0 \mathrm{D}$ dimer crystal structure or $2 \mathrm{D}$ layered crystal structure. For example, $\mathrm{Cs}_{3} \mathrm{Sb}_{2} \mathrm{I}_{9}$ with a $2 \mathrm{D}$ layered crystal structure is formed at $250{ }^{\circ} \mathrm{C}$, while $\mathrm{Cs}_{3} \mathrm{Sb}_{2} \mathrm{I}_{9}$ with a 0D dimer crystal structure is formed at $150{ }^{\circ} \mathrm{C} .{ }^{92}$ The layered structure has a direct band gap of $2.05 \mathrm{eV}$, while it is $2.3 \mathrm{eV}$ for the dimer structured materials. With the structure of ITO/ PEDOT:PSS/Cs ${ }_{3} \mathrm{Sb}_{2} \mathrm{I}_{9} / \mathrm{PC}_{70} \mathrm{BM} / \mathrm{C}_{60} / \mathrm{BCP} / \mathrm{Al}$, the devices based on $\mathrm{Cs}_{3} \mathrm{Sb}_{2} \mathrm{I}_{9}$ with layered and dimer structures achieved PCE of 
Table 2 Properties of perovskite-derived materials and their device efficiencies

\begin{tabular}{llllll}
\hline Materials & $E_{\mathrm{g}}(\mathrm{eV})$ & $\mathrm{HTL}$ & $\mathrm{ETL}$ & PCE/\% & Ref. \\
\hline $\mathrm{Cs}_{2} \mathrm{SnI}_{6}$ & 1.48 & $\mathrm{P} 3 \mathrm{HT}$ & $\mathrm{TiO}_{2}$ & 0.96 & 81 \\
$\mathrm{Cs}_{2} \mathrm{SnI}_{5} \mathrm{Br}$ & 1.56 & $\mathrm{Cs}_{2} \mathrm{SnI}_{6}$ & $\mathrm{TiO}_{2}$ & 1.6 & 82 \\
$\mathrm{Cs}_{2} \mathrm{SnI}_{4} \mathrm{Br}_{2}$ & 1.58 & $\mathrm{Cs}_{2} \mathrm{SnI}_{6}$ & $\mathrm{TiO}_{2}$ & 2.1 & 82 \\
$\mathrm{Cs}_{2} \mathrm{SnI}_{2} \mathrm{Br}_{4}$ & 1.81 & $\mathrm{Cs}_{2} \mathrm{SnI}_{6}$ & $\mathrm{TiO}_{2}$ & 1.08 & 82 \\
$\mathrm{Cs}_{2} \mathrm{SnIBr}_{5}$ & 2.36 & $\mathrm{Cs}_{2} \mathrm{SnI}_{6}$ & $\mathrm{TiO}_{2}$ & 0.002 & 82 \\
$\mathrm{Cs}_{2} \mathrm{SnBr}_{6}$ & 2.85 & $\mathrm{Cs}_{2} \mathrm{SnI}_{6}$ & $\mathrm{TiO}_{2}$ & & 82 \\
$\mathrm{Cs}_{2} \mathrm{PdBr}_{6}$ & 1.6 & & & & 83 \\
$\mathrm{Cs}_{2} \mathrm{TiBr}_{6}$ & 1.8 & P3HT & $\mathrm{TiO}_{2}$ & 3.3 & 96 \\
$\mathrm{Cs}_{3} \mathrm{Bi}_{2} \mathrm{I}_{9}$ & 2.1 & Spiro-MeOTAD & $\mathrm{TiO}_{2}$ & 1.09 & 85 \\
$\mathrm{CsBi}_{3} \mathrm{I}_{10}$ & 1.77 & P3HT & $\mathrm{TiO}_{2}$ & 0.4 & 89 \\
$\mathrm{CsBi}_{3} \mathrm{I}_{10}$ & & & $\mathrm{TiO}_{2}$ & 1.51 & 90 \\
$\mathrm{Cs}_{3} \mathrm{Sb}_{2} \mathrm{I}_{9}$ & 2.05 & PEDOT:PSS & $\mathrm{PC}_{70} \mathrm{BM}$ & 1.5 & 92 \\
$\mathrm{AgBi}_{2} \mathrm{I}_{7}$ & 1.87 & P3HT & $\mathrm{TiO}_{2}$ & 1.22 & 93 \\
$\mathrm{Ag}_{2} \mathrm{BiI}_{5}$ & 1.85 & P3HT & $\mathrm{TiO}_{2}$ & 2.1 & 94 \\
$\mathrm{AgBiI}_{4}$ & 1.86 & PTAA & $\mathrm{TiO}_{2}$ & 2.1 & 95 \\
$\mathrm{Ag}_{3} \mathrm{BiI}_{6}$ & 1.83 & PTAA & $\mathrm{TiO}_{2}$ & 4.3 & 28 \\
\hline
\end{tabular}

$1.5 \%$ and $0.89 \%$, respectively. The difference can be ascribed to the lower band gap and higher carrier mobility of the former. ${ }^{86}$ This structure has more deep level defects, which can serve as the center of non-radiative recombination, thus disrupting the device performance. ${ }^{91}$ It is vital to note that even though perovskite-derived materials with the $\mathrm{A}_{3} \mathrm{~B}_{2} \mathrm{X}_{9}$ formula have great potential in the field of optoelectronics, unfortunately, their band gaps are relatively large, and these materials have many defects, which may restrict the further development of device performance based on such materials. In summary, these types of materials need to be examined further, especially their structural regulation.

\section{$5.3 \quad \mathrm{Ag}_{a} \mathrm{Bi}_{b} \mathbf{I}_{a+3 b}$ formula}

Compared to low-dimensional materials, 3D materials are more conducive to $\mathrm{PV}$ applications considering their semiconductor properties. Transition metal monovalent silver and copper cations $\left(\mathrm{Ag}^{+}\right.$and $\left.\mathrm{Cu}^{+}\right)$have been introduced into iodobismuthate materials to form 3D structures ${ }^{86}$ For example, a synthetic air-stabilized $\mathrm{Ag}$-Bi-I film was proposed for the fabrication of the $\mathrm{AgBi}_{2} \mathrm{I}_{7}$ film. AgI and $\mathrm{BiI}_{3}$ were dissolved in $n$-butylamine solvent to obtain a precursor solution and the precursor was annealed at $150{ }^{\circ} \mathrm{C}$ to remove $n$-butylamine, which previously was bound to the silver iodide and bismuth iodide complexes. ${ }^{93}$ The $\mathrm{AgBi}_{2} \mathrm{I}_{7}$ film was determined to be a cubic structure with an $E_{\mathrm{g}}$ of $1.87 \mathrm{eV}$. As a result, the solar cell devices produced a $J_{\mathrm{SC}}$ of $3.30 \mathrm{~mA} \mathrm{~cm}{ }^{-2}$, a $V_{\mathrm{OC}}$ of $0.56 \mathrm{~V}$, an FF of 0.67 , and a PCE of $1.22 \%$. It was found that the device retained $93 \%$ of its PCE upon initial exposure to the external environment after 10 days, indicating the device had great stability. ${ }^{93} \mathrm{~A}$ further improvement in PCE to $2.1 \%$ was obtained using an $\mathrm{Ag}_{2} \mathrm{BiI}_{5}$ film with a hexagonal structure and $E_{\mathrm{g}}$ of $1.85 \mathrm{eV}$. Photocurrent generation was observed between $350 \mathrm{~nm}$ and $700 \mathrm{~nm}$, and the maximum external quantum efficiency of about $45 \%$ was obtained. ${ }^{94} \mathrm{AgBiI}_{4}$ as a lead-free light absorbing material was further synthesized via the solution-based thin film method and assembled in mesoporous solar cell devices. ${ }^{95} \mathrm{~A}$ dense and smooth $\mathrm{AgBiI}_{4}$ film was obtained by treatment with an antisolvent during spin coating and subsequent annealing. AgBiI ${ }_{4}$ has a low $E_{\mathrm{g}}$ of $1.86 \mathrm{eV}$ and an absorption spectrum in the range of $400 \mathrm{~nm}$ to $720 \mathrm{~nm}$, which is suitable for light trapping in thin film solar cells. By using different HTLs (PTAA and P3HT) in the device, better energy alignment between PTAA and $\mathrm{AgBiI}_{4}$ resulted in more efficient hole extraction efficiency in the active material and a higher PCE of $2.1 \%$. The device also exhibited excellent long-term air stability, maintaining $96 \%$ of its initial PCE even after 1000 hours in relative humidity of $26 \% .^{95}$ Turkevych $e$ al. studied the structure and optoelectronic properties of a promising family of stable $\mathrm{Pb}$-free photovoltaic halides with the general formula $\mathrm{Ag}_{a} \mathrm{Bi}_{b} \mathrm{I}_{x}(x=a+3 b)$ including nominal compositions of $\mathrm{Ag}_{3} \mathrm{BiI}_{6}, \mathrm{Ag}_{2} \mathrm{BiI}_{5}, \mathrm{AgBiI}_{4}$, and $\mathrm{AgBi}_{2} \mathrm{I}_{7}$. The $\mathrm{Ag}-$ $\mathrm{Bi}-\mathrm{I}$ ternary group reveals three-dimensional structures of edgesharing $\left[\mathrm{AgI}_{6}\right]$ and $\left[\mathrm{BiI}_{6}\right]$ octahedra. ${ }^{28}$ The $\mathrm{Ag}-\mathrm{Bi}-\mathrm{I}$ compositions have direct optical band gaps in the range of 1.79-1.83 eV. Though AgI is insoluble in DMSO, the mixture of AgI and $\mathrm{BiI}_{3}$ is readily soluble in hot DMSO at $110{ }^{\circ} \mathrm{C}$ due to the formation of $\left[\mathrm{BiI}_{3+x}\right]^{x-}$ complex ions. Therefore, solar cell devices can be fabricated with the solution-processed method, reaching a PCE of $4.3 \%$ with a $J_{\mathrm{SC}}$ of $10.7 \mathrm{~mA} \mathrm{~cm}{ }^{-2}, V_{\mathrm{OC}}$ of $0.63 \mathrm{~V}$, an FF of 0.64 . This indicates that silver-bismuth halide materials have great potential as lead-free light absorbers for PSCs. A summary of the optical data structure and structure based on perovskite-derived materials and also their performances as absorbing materials in $\mathrm{PV}$ devices are given in Table 2. It is worth mentioning that there are still a few studies on perovskite-derived materials. Most of the research has focused on the optoelectronic properties of material and there is still a lack of research on the fabrication process and structure optimization for better performance. Although, considering various aspects, these materials can meet the requirements as a light absorbing layer, the current photoelectric conversion efficiency produced from the devices has not exceeded expectation. Therefore, optimizing the components of the device and its interface and also matching the hole transport layer and electron transport layer materials of different energy levels according to different light absorbing materials have become important directions in future research.

\section{Conclusion and outlooks}

The recent progress on the research on perovskite solar cells has been systematically reviewed. It may be a stretch to compare these strategies in PSCs to the "Emperor's New Clothes". After all, the dictionary definition of strategy is so broad that virtually any declarative sentence that expresses some form of desire qualifies as a strategy. However, in the real world, a true strategy has to have a tangible plan and a clear program to implement that plan. This means making difficult trade-offs and setting clear priorities. However, unfortunately, most of these so-called effective strategies published in top journals, including Science and Nature, based on the selection criterion of 'THE FIRST' and/ or 'THE BEST' have failed in practice and reproduction. Furthermore, most of them did not address any of the major problems in environmental security and national programs created by the existing fundamental debate or the far more 
serious issues raised on ethics for the future of humans. We note that inorganic lead-free perovskite materials generally have greater light absorption properties, thermal stability, and environmental friendliness compared to lead-containing perovskite materials. The highest PCE achieved for an inorganic lead-free perovskite solar cell was $4.81 \%$ for $\mathrm{CsSnX}_{3}$, but with poor air stability. In the case of the double-perovskite inorganic lead-free material, due to the difficulty in preparation of high-quality films, only $\mathrm{Cs}_{2} \mathrm{AgBiBr}_{6}$ was successfully used in device fabrication with an efficiency of less than $2 \%$. Perovskite-derived materials such as $\mathrm{Ag}_{a} \mathrm{Bi}_{b} \mathrm{I}_{x}$ have exhibited potential in solar cell application with a PCE of about $4.3 \%$. In addition to $\mathrm{Cs}$ and $\mathrm{Rb}$, the use of other cations at the $\mathrm{A}$ site of the perovskite material is likely to achieve considerable performance. It is fair that the use of inorganic lead-free perovskite materials as a light-absorbing layer is in its infancy, and their solar cell efficiency cannot be compared to that of traditional organic-inorganic hybrid perovskites yet. This requires further comprehensive and systematic research on structural composition, high-quality film preparation, and development of new inorganic lead-free perovskite materials, electron transport layers and hole transport layers. Composition engineering of this type of material can be the focus of research to further enhance its photoelectric performances. A blend of elements in the $\mathrm{A}, \mathrm{B}$, and $\mathrm{X}$ sites of the perovskite composition can be plausible in this case. In addition, effective methods have to be developed for the preparation of high quality films, including chemical vapor deposition and dynamic hot-casting techniques. More importantly, solar cell device characterization for most of the new inorganic lead-free materials needs to be fulfilled urgently. Therefore, there is no doubt that novel inorganic lead-free perovskite solar cells still have a lot of space for exploration. Selecting appropriate electron transport layer and hole transport layer materials is beneficial to improve the PCE of solar cells. The commercialization of perovskite solar cells requires extensive research and development of new perovskite materials that are not only very effective in photoelectric conversion but also non-toxic and stable. Thus, in the next few years, more efforts are required for the development of inorganic lead-free perovskite solar cells.

\section{Conflicts of interest}

There are no conflicts to declare.

\section{Acknowledgements}

The authors acknowledge financial support from the Natural Science Foundation of China (No. 21673091), the NSFC Major International (Regional) Joint Research Project NSFC-SNSF (No. 51661135023), the Natural Science Foundation of Hubei Province (No. 2015CFA125), the Central Universities of Huazhong University of Science \& Technology (2018KFYXKJC034), and the Double first-class research funding of China-EU Institute for Clean and Renewable Energy (3011187029).

\section{References}

1 D. Wang, M. Wright, N. K. Elumalai and A. Uddin, Sol. Energy Mater. Sol. Cells, 2016, 147, 255-275.

2 Q. Sun, X. Gong, H. Li, S. Liu, X. Zhao, Y. Shen and M. Wang, Sol. Energy Mater. Sol. Cells, 2018, 185, 111-116.

3 M. Green, A. Ho-Baillie and H. Snaith, Nat. Photonics, 2014, 8, 506-514.

4 N. Rolston, A. Printz, J. Tracy, H. Weerasinghe, D. Vak, L. Haur, A. Priyadarshi, N. Mathews, D. Slotcavage, M. McGehee, R. Kalan, K. Zielinski, R. Grimm, H. Tsai, W. Nie, A. Mohite, S. Gholipour, M. Saliba, M. Grätzel and R. H. Dauskardt, Adv. Energy Mater., 2018, 8, 1702116.

5 H. Li, J. Lu, T. Zhang, Y. Shen and M. Wang, ACS Energy Lett., 2018, 3, 1815-1823.

6 X. Zhao and M. Wang, Materials Today Energy, 2018, 7, 208220.

7 J. Huang, Y. Yuan, Y. Shao and Y. Yan, Nat. Rev. Mater., 2017, 2, 17042.

8 X. Zhao, L. Tao, H. Li, W. Huang, P. Sun, J. Liu, S. Liu, Q. Sun, Z. Cui, L. Sun, Y. Shen, Y. Yang and M. Wang, Nano Lett., 2018, 18, 2442-2449.

9 Z. Chen, Z. Chen, H. Li, X. Zhao, M. Zhu and M. Wang, Adv. Opt. Mater., 2018, 6, 1800221.

10 D. Li, P. Liao, X. Shai, W. Huang, S. Liu, H. Li, Y. Shen and M. Wang, RSC Adv. , 2016, 6, 89356-89366.

11 T. Leijtens, G. Eperon, N. Noel, S. Habisreutinger, A. Petrozza and H. Snaith, Adv. Energy Mater., 2015, 5, 1500963.

12 X. Xu and M. Wang, Sci. China: Chem., 2016, 60, 396-404.

13 T. Leijtens, G. Eperon, N. Noel, S. Habisreutinger, A. Petrozza and H. Snaith, Adv. Energy Mater., 2015, 5, 1500963-1500985.

14 N. Aristidou, I. Sanchez-Molina, T. Chotchuangchutchaval, M. Brown, L. Martinez, T. Rath and S. Haque, Angew. Chem., Int. Ed., 2015, 54, 8208-8212.

15 M. Asghar, J. Zhang, H. Wang and P. Lund, Renewable Sustainable Energy Rev., 2017, 77, 131-146.

16 T. A. Berhe, W. Su, C. Chen, C. Pan, J. Cheng, H. Chen, M. Tsai, L. Chen, A. Dubale and B. Hwang, Energy Environ. Sci., 2016, 9, 323-356.

17 X. Zhao and N. Park, ACS Photonics, 2015, 2, 1139-1151.

18 N. Tiep, Z. Ku and H. Fan, Adv. Energy Mater., 2016, 6, 1501420.

19 M. Shahbazi and H. Wang, Sol. Energy, 2016, 123, 74-87.

20 Z. Wang, Z. Shi, T. Li, Y. Chen and W. Huang, J. Am. Chem. Soc., 2017, 36, 1190-1212.

21 Q. Fu, X. Tang, B. Huang, T. Hu, L. Tan, L. Chen and Y. Chen, Adv. Sci., 2018, 5, 1700387.

22 B. Li, Y. Li, C. Zheng, D. Gao and W. Huang, RSC Adv., 2016, 6, 38079-38091.

23 B. Salhi, Y. Wudil, M. Hossain, A. Al-Ahmed and F. AlSulaiman, Renewable Sustainable Energy Rev., 2018, 90, 210-222.

24 M. Wang, Sci. Bull., 2016, 62, 249-255.

25 A. Abate, Joule, 2017, 1, 659-664. 
26 X. Shai, L. Zuo, P. Sun, P. Liao, W. Huang, E. Yao, H. Li, S. Liu, Y. Shen, Y. Yang and M. Wang, Nano Energy, 2017, 36, 213-222.

27 X. Shai, J. Wang, P. Sun, W. Huang, P. Liao, F. Cheng, B. Zhu, S. Chang, E. Yao, Y. Shen, L. Miao, Y. Yang and M. Wang, Nano Energy, 2018, 48, 117-127.

28 I. Turkevych, S. Kazaoui, E. Ito, T. Urano, K. Yamada, H. Tomiyasu, H. Yamagishi, M. Kondo and S. Aramaki, ChemSusChem, 2017, 10, 3754-3759.

29 A. Babayigit, A. Ethirajan, M. Muller and B. Conings, Nat. Mater., 2016, 15, 247-251.

30 I. Benmessaoud, A. Mahul-Mellier, E. Horvath, B. Maco, M. Spina, H. Lashuel and L. Forro, Toxicol. Res., 2016, 5, 407-419.

31 N. Espinosa, L. Serrano-Luján, A. Urbina and F. Krebs, Sol. Energy Mater. Sol. Cells, 2015, 137, 303-310.

32 J. Ball and A. Petrozza, Nat. Energy, 2016, 1, 16149.

33 M. Filip, X. Liu, A. Miglio, G. Hautier and F. Giustino, J. Phys. Chem. C, 2017, 122, 158-170.

34 X. Zhao, J. Yang, Y. Fu, D. Yang, Q. Xu, L. Yu, S. Wei and L. Zhang, J. Am. Chem. Soc., 2017, 139, 2630-2638.

35 T. Jellicoe, J. Richter, H. Glass, M. Tabachnyk, R. Brady, S. Dutton, A. Rao, R. Friend, D. Credgington, N. Greenham and M. L. Bohm, J. Am. Chem. Soc., 2016, 138, 2941-2944.

36 X. Zhou, J. Jankowska, H. Dong and O. V. Prezhdo, J. Energy Chem., 2017, 26, 21-49.

37 P.-F. Li, Y.-Y. Tang, W.-Q. Liao, H.-Y. Ye, Y. Zhang, D.-W. Fu, Y.-M. You and R.-G. Xiong, NPG Asia Mater., 2017, 9, e342.

38 B. Saparov and D. B. Mitzi, Chem. Rev., 2016, 116, 4558-4596. 39 F. Hao, C. Stoumpos, D. Cao, R. Chang and M. Kanatzidis, Nat. Photonics, 2014, 8, 489-494.

$40 \mathrm{~W}$. Travis, E. Glover, H. Bronstein, D. Scanlon and R. Palgrave, Chem. Sci., 2016, 7, 4548-4556.

41 X. He, Y. Qiu and S. Yang, Adv. Mater., 2017, 29, 1700775.

42 W. Zhang, G. Eperon and H. Snaith, Nat. Energy, 2016, 1, 16048.

43 M. Saidaminov, O. Mohammed and O. Bakr, ACS Energy Lett., 2017, 2, 889-896.

44 M. Petrus, J. Schlipf, C. Li, T. Gujar, N. Giesbrecht, P. MüllerBuschbaum, M. Thelakkat, T. Bein, S. Hüttner and P. Docampo, Adv. Energy Mater., 2017, 7, 1700264.

45 M. Green and A. Ho-Baillie, ACS Energy Lett., 2017, 2, 822830.

46 Q. Zhang, F. Hao, J. Li, Y. Zhou, Y. Wei and H. Lin, Sci. Technol. Adv. Mater., 2018, 19, 425-442.

47 J. Im, C. Stoumpos, H. Jin, A. Freeman and M. Kanatzidis, J. Phys. Chem. Lett., 2015, 6, 3503-3509.

48 J. Feng, APL Mater., 2014, 2, 081801.

49 G. Lin, Y. Lin, H. Huang, R. Cui, X. Guo, B. Liu, J. Dong, X. Guo and B. Sun, Nano Energy, 2016, 27, 638-646.

50 K. Shum, Z. Chen, J. Qureshi, C. Yu, J. Wang, W. Pfenninger, N. Vockic, J. Midgley and J. Kenney, Appl. Phys. Lett., 2010, 96, 221903.

51 I. Chung, J. Song, J. Im, J. Androulakis, C. Malliakas, H. Li, A. Freeman, J. Kenney and M. Kanatzidis, J. Am. Chem. Soc., 2012, 134, 8579-8587.
52 M. Konstantakou and T. Stergiopoulos, J. Mater. Chem. A, 2017, 5, 11518-11549.

53 Z. Chen, J. Wang, Y. Ren, C. Yu and K. Shum, Appl. Phys. Lett., 2012, 101, 093901.

54 M. Kumar, S. Dharani, W. Leong, P. Boix, R. Prabhakar, T. Baikie, C. Shi, H. Ding, R. Ramesh, M. Asta, M. Graetzel, S. Mhaisalkar and N. Mathews, Adv. Mater., 2014, 26, 7122-7127.

55 T. Song, T. Yokoyama, S. Aramaki and M. Kanatzidis, ACS Energy Lett., 2017, 2, 897-903.

56 K. Marshall, M. Walker, R. Walton and R. Hatton, Nat. Energy, 2016, 1, 1-13.

57 K. Marshall, R. Walton and R. Hatton, J. Mater. Chem. A, 2015, 3, 11631-11640.

58 T. Song, T. Yokoyama, C. Stoumpos, J. Logsdon, D. Cao, M. Wasielewski, S. Aramaki and M. Kanatzidis, J. Am. Chem. Soc., 2017, 139, 836-842.

59 N. Wang, Y. Zhou, M. Ju, H. Garces, T. Ding, S. Pang, X. Zeng, N. Padture and X. Sun, Adv. Energy Mater., 2016, 6, 1601130.

60 D. Sabba, H. Mulmudi, R. Prabhakar, T. Krishnamoorthy, T. Baikie, P. Boix, S. Mhaisalkar and N. Mathews, J. Phys. Chem. C, 2015, 119, 1763-1767.

61 W. Li, J. Li, J. Li, J. Fan, Y. Mai and L. Wang, J. Mater. Chem. A, 2016, 4, 17104-17110.

62 S. Gupta, T. Bendikov, G. Hodes and D. Cahen, ACS Energy Lett., 2016, 1, 1028-1033.

63 K. Marshall, S. Tao, M. Walker, D. Cook, J. Lloyd-Hughes, S. Varagnolo, A. Wijesekara, D. Walker, R. I. Walton and R. Hatton, Mater. Chem. Front., 2018, 2, 1515-1522.

64 J. Jiang, C. Onwudinanti, R. Hatton, P. Bobbert and S. Tao, J. Phys. Chem. C, 2018, 122, 17660-17667.

65 X. Mao, L. Sun, T. Wu, T. Chu, W. Deng and K. Han, J. Phys. Chem. C, 2018, 122, 7670-7675.

66 W. Ming, H. Shi and M. Du, J. Mater. Chem. A, 2016, 4, 1385213858.

67 T. Krishnamoorthy, H. Ding, C. Yan, W. Leong, T. Baikie, Z. Zhang, M. Sherburne, S. Li, M. Asta, N. Mathews and S. Mhaisalkar, J. Mater. Chem. A, 2015, 3, 23829-23832.

68 M. Roknuzzaman, K. Ostrikov, H. Wang, A. Du and T. Tesfamichael, Sci. Rep., 2017, 7, 14025.

69 P. Cheng, T. Wu, J. Liu, W. Deng and K. Han, J. Phys. Chem. Lett., 2018, 9, 2518-2522.

70 A. Slavney, T. Hu, A. Lindenberg and H. Karunadasa, J. Am. Chem. Soc., 2016, 138, 2138-2141.

71 C. Savory, A. Walsh and D. Scanlon, ACS Energy Lett., 2016, 1, 949-955.

72 E. McClure, M. Ball, W. Windl and P. Woodward, Chem. Mater., 2016, 28, 1348-1354.

73 C. Wu, Q. Zhang, Y. Liu, W. Luo, X. Guo, Z. Huang, H. Ting, W. Sun, X. Zhong, S. Wei, S. Wang, Z. Chen and L. Xiao, Adv. Sci., 2018, 5, 1700759.

74 E. Greul, M. L. Petrus, A. Binek, P. Docampo and T. Bein, J. Mater. Chem. A, 2017, 5, 19972-19981.

75 K. Du, W. Meng, X. Wang, Y. Yan and D. Mitzi, Angew. Chem., Int. Ed., 2017, 56, 8158-8162. 
76 X. J. Liu, K. Matsuda, Y. Moritomo, A. Nakamura and N. Kojima, Phys. Rev. B: Condens. Matter Mater. Phys., 1999, 59, 7925-7930.

77 L. Debbichi, S. Lee, H. Cho, A. Rappe, K. H. Hong, M. Jang and H. Kim, Adv. Mater., 2018, 30, e1707001.

78 G. Gou, J. Young, X. Liu and J. M. Rondinelli, Inorg. Chem., 2017, 56, 26-32.

79 Z. Xiao, Y. Zhou, H. Hosono and T. Kamiya, Phys. Chem. Chem. Phys., 2015, 17, 18900-18903.

80 B. Lee, C. Stoumpos, N. Zhou, F. Hao, C. Malliakas, C. Yeh, T. Marks, M. Kanatzidis and R. Chang, J. Am. Chem. Soc., 2014, 136, 15379-15385.

81 X. Qiu, B. Cao, S. Yuan, X. Chen, Z. Qiu, Y. Jiang, Q. Ye, H. Wang, H. Zeng, J. Liu and M. Kanatzidis, Sol. Energy Mater. Sol. Cells, 2017, 159, 227-234.

82 B. Lee, A. Krenselewski, S. Baik, D. Seidman and R. Chang, Sustainable Energy Fuels, 2017, 1, 710-724.

83 M. Filip, P. Nayak, S. Nayak, A. Ramadan, Z. Wang, F. Giustino and H. Snaith, J. Am. Chem. Soc., 2017, 139, 6030-6033.

84 M. Ju, M. Chen, Y. Zhou, H. Garces, J. Dai, L. Ma, N. Padture and X. Zeng, ACS Energy Lett., 2018, 3, 297-304.

85 B. Park, B. Philippe, X. Zhang, H. Rensmo, G. Boschloo and E. Johansson, Adv. Mater., 2015, 27, 6806-6813.

86 H. Chen, S. Xiang, W. Li, H. Liu, L. Zhu and S. Yang, Sol. RRL, 2018, 2, 1700188 .
87 B. Ghosh, S. Chakraborty, H. Wei, C. Guet, S. Li, S. Mhaisalkar and N. Mathews, J. Phys. Chem. C, 2017, 121, 17062-17067.

88 B. Ghosh, B. Wu, H. Mulmudi, C. Guet, K. Weber, T. Sum, S. Mhaisalkar and N. Mathews, ACS Appl. Mater. Interfaces, 2018, 10, 35000-35007.

89 M. Johansson, H. Zhu and E. Johansson, J. Phys. Chem. Lett., 2016, 7, 3467-3471.

90 J. Shin, M. Kim, S. Jung, C. Kim, J. Park, A. Song, K. Chung, S. Jin, J. Lee and M. Song, Nano Res., 2018, 11, 6283-6293.

91 B. Saparov, F. Hong, J. Sun, H. Duan, W. Meng, S. Cameron, I. Hill, Y. Yan and D. Mitzi, Chem. Mater., 2015, 27, 56225632.

92 A. Singh, K. Boopathi, A. Mohapatra, Y. Chen, G. Li and C. Chu, ACS Appl. Mater. Interfaces, 2018, 10, 2566-2573.

93 Y. Kim, Z. Yang, A. Jain, O. Voznyy, G. Kim, M. Liu, L. Quan, F. Garcia de Arquer, R. Comin, J. Fan and E. Sargent, Angew. Chem., Int. Ed., 2016, 55, 9586-9590.

$94 \mathrm{H}$. Zhu, M. Pan, M. Johansson and E. Johansson, ChemSusChem, 2017, 10, 2592-2596.

95 C. Lu, J. Zhang, H. Sun, D. Hou, X. Gan, M. Shang, Y. Li, Z. Hu, Y. Zhu and L. Han, ACS Appl. Mater. Interfaces, 2018, 1, 4485-4492.

96 M. Chen, M. Ju, A. Carl, Y. Zong, R. Grimm, J. Gu, X. Zeng, Y. Zhou and N. Padture, Joule, 2018, 2, 558-570. 